\title{
American College of Gastroenterology Guideline on the Management of Helicobacter pylori Infection
}

\author{
William D. Chey, M.D., F.A.C.G., A.G.A.F., F.A.C.P., ${ }^{1}$ Benjamin C.Y. Wong, M.D., Ph.D., F.A.C.G., F.A.C.P. ${ }^{2}$, \\ and the Practice Parameters Committee of the American College of Gastroenterology \\ ${ }^{1}$ University of Michigan Medical Center, Ann Arbor, Michigan; and ${ }^{2}$ Department of Medicine, University \\ of Hong Kong, Hong Kong
}

\begin{abstract}
Helicobacter pylori (H. pylori) remains a prevalent, worldwide, chronic infection. Though the prevalence of this infection appears to be decreasing in many parts of the world, $H$. pylori remains an important factor linked to the development of peptic ulcer disease, gastric malignanc and dyspeptic symptoms. Whether to test for $\boldsymbol{H}$. pylori in patients with functional dyspepsia, gastroesophageal reflux disease (GERD), patients taking nonsteroidal antiinflammatory drugs, with iron deficiency anemia, or who are at greater risk of developing gastric cancer remains controversial. H. pylori can be diagnosed by endoscopic or nonendoscopic methods. A variety of factors including the need for endoscopy, pretest probability of infection, local availability, and an understanding of the performance characteristics and cost of the individual tests influences choice of evaluation in a given patient. Testing to prove eradication should be performed in patients who receive treatment of $H$. pylori for peptic ulcer disease, individuals with persistent dyspeptic symptoms despite the test-and-treat strategy, those with $H$. pylori-associated MALT lymphoma, and individuals who have undergone resection of early gastric cancer. Recent studies suggest that eradication rates achieved by first-line treatment with a proton pump inhibitor (PPI), clarithromycin, and amoxicillin have decreased to $70-85 \%$, in part due to increasing clarithromycin resistance. Eradication rates may also be lower with 7 versus 14-day regimens. Bismuth-containing quadruple regimens for 7-14 days are another first-line treatment option. Sequential therapy for 10 days has shown promise in Europe but requires validation in North America. The most commonly used salvage regimen in patients with persistent $H$. pylori is bismuth quadruple therapy. Recent data suggest that a PPI, levofloxacin, and amoxicillin for 10 days is more effective and better tolerated than bismuth quadruple therapy for persistent $H$. pylori infection, though this needs to be validated in the United States.
\end{abstract}

(Am J Gastroenterol 2007;102:1808-1825)

\section{INTRODUCTION AND PREAMBLE}

Helicobacter pylori (H. pylori) remains one of the most common worldwide human infections and is associated with a number of important upper gastrointestinal (GI) conditions including chronic gastritis, peptic ulcer disease, and gastric malignancy. The prevalence of $H$. pylori is closely tied to socioeconomic conditions and accordingly, this infection is more common in developing countries than in developed countries such as the United States (1). Regardless, it has been estimated that $30-40 \%$ of the U.S. population is infected with $H$. pylori (2). The vast majority of individuals acquire this infection during childhood. Based upon this observation and the fact that $H$. pylori infection rates in children are decreasing, it is likely that the population-based prevalence of $H$. pylori in the United States will continue to fall in the coming years.

Guidelines for the management of $H$. pylori infection were last published by the American College of Gastroenterology in 1998 (3). Since that time, a significant amount of new information regarding the management of this infection has become available. Because of this, the authors, Practice Parameters Committee, and Governing Board of the Amer- ican College of Gastroenterology have produced this updated management guideline to assist clinicians caring for patients with $\mathrm{H}$. pylori infection. To accomplish this task, literature searches using Medline, PubMed, and the Cochrane Database were performed as part of the preparation for this management guideline. The document makes summary recommendations (italicized statements) followed by a more detailed description of the supporting evidence and rationale for arriving at the topline recommendation. As with all guidelines, this document attempts to provide the preferred, but not the only, means by which to diagnose and treat $\mathrm{H}$. pylori infection. Specific issues, which may or may not be discussed in this document, will always influence the best course of action to be taken in an individual patient.

\section{WHAT ARE THE CLEAR INDICATIONS FOR DIAGNOSING AND TREATING H. PYLORI INFECTION?}

\section{Recommendation}

- Testing for $\mathrm{H}$. pylori infection is indicated in patients with active peptic ulcer disease, a past history of documented peptic ulcer, or gastric MALT lymphoma. 
- The test-and-treat strategy for $\mathrm{H}$. pylori infection is a proven management strategy for patients with uninvestigated dyspepsia who are under the age of $55 \mathrm{yr}$ and have no "alarm features" (bleeding, anemia, early satiety, unexplained weight loss, progressive dysphagia, odynophagia, recurrent vomiting, family history of GI cancer, previous esophagogastric malignancy).

Although the majority of those infected remain clinically silent, there are a number of well-established clinical conditions that have been associated with $H$. pylori infection. The indications for the diagnosis and treatment of $H$. pylori infection are listed in Table 1.

DUODENAL AND GASTRIC ULCER. There is a clear link between $H$. pylori infection and the pathogenesis of peptic ulcer disease (PUD) (4). Given the overwhelming evidence supporting this relationship, few would question the clinical and economic merits of $H$. pylori eradication in a patient with PUD. A meta-analysis including 24 randomized controlled trials and randomized comparative trials including $2,102 \mathrm{pa}-$ tients with PUD revealed that the 12-month ulcer remission rate was $97 \%$ (95\% CI 95-99\%) for gastric ulcer, and 98\% (95\% CI 97-99\%) for duodenal ulcer in patients successfully eradicated of $H$. pylori infection, compared with $61 \%$ (95\% CI 52-70\%) for gastric ulcer and 65\% (95\% CI 50$65 \%$ ) for duodenal ulcer in those with persistent infection (5). Recently, a meta-analysis by Ford et al., including 52 trials, demonstrated that $H$. pylori eradication therapy yielded superior healing rates for duodenal ulcer but not gastric ulcer compared with short courses of ulcer healing medications such as histamine-2 receptor antagoinists $\left(\mathrm{H}_{2} \mathrm{RAs}\right)$ or proton pump inhibitors (PPIs). This study found that $H$. pylori eradication was superior to no treatment in preventing duodenal and gastric ulcer recurrence. H. pylori eradication was also superior to maintenance therapy with acid suppressive medications in preventing gastric ulcer but not duodenal ulcer recurrence (6). In a Markov model analysis, H. pylori eradication was cost-effective for duodenal ulcer over $1 \mathrm{yr}$ and gastric ulcer over 2 yr. The authors concluded that $H$.

Table 1. Indications for Diagnosis and Treatment of $H$. pylori

\begin{tabular}{l} 
Established \\
- Active peptic ulcer disease (gastric or duodenal ulcer) \\
- Confirmed history of peptic ulcer disease (not previously \\
treated for H. pylori) \\
- Gastric MALT lymphoma (low grade) \\
- After endoscopic resection of early gastric cancer \\
- Uninvestigated dyspepsia (depending upon H. pylori \\
prevalence) \\
Controversial \\
- Nonulcer dyspepsia \\
- Gastroesophageal reflux disease \\
- Persons using nonsteroidal antiinflammatory drugs \\
- Unexplained iron deficiency anemia \\
\hline
\end{tabular}

pylori eradication reduces the recurrence of PUD and is costeffective (6).

GASTRODUODENAL BLEEDING. Sharma and colleagues performed a meta-analysis to compare the effectiveness of eradicating $H$. pylori infection with other approaches to prevent recurrent ulcer hemorrhage as well as a cost minimization analysis to determine the least costly strategy. They found that $H$. pylori treatment decreased recurrent bleeding by $17 \%$ and $4 \%$ compared with ulcer healing treatment alone (bismuth $120 \mathrm{mg}$ q.i.d to ulcer healing, ranitidine $300 \mathrm{mg}$ q.h.s. for $16 \mathrm{wk}$ or omeprazole $20 \mathrm{mg}$ q.d. for $2 \mathrm{wk}$ ) or ulcer healing treatment followed by maintenance therapy (ranitidine 150-300 mg q.h.s. or omeprazole $20 \mathrm{mg}$ q.d. for 12 24 months), respectively (7). A 5-yr prospective, randomized, controlled study by Liu et al. in 82 Taiwanese patients with a history of ulcer bleeding demonstrated that maintenance acid suppression was not routinely necessary to prevent ulcer recurrence after successful $H$. pylori eradication and ulcer healing (8). Results from these studies have been confirmed by a recent Cochrane systematic review (9)

\section{Gastric MALT Lymphoma}

A growing body of literature from nonrandomized observational trials supports the importance of $H$. pylori infection in the pathogenesis and natural history of mucosa associated lymphoid tissue (MALT) lymphoma $(10,11)$. For localized gastric MALT lymphoma, $H$. pylori treatment achieves tumor regression in $60-90 \%$ of patients (11). Several recent prospective studies have addressed the long-term outcome of gastric MALT lymphoma after eradication of $H$. pylori infection. These reports suggest that $H$. pylori eradication provides durable remission in patients with low-grade MALT lymphoma with recurrence rates of 3-13\% over $5 \mathrm{yr}$ of followup (12-14). Finally, Chen and colleagues evaluated a trial of 24 patients with high-grade transformed tumors (diffuse large B-cell with features of MALT, DLBCL [MALT] lymphoma). H. pylori eradication led to complete remission in $64 \%(95 \%$ CI $42-86 \%$ ) (14). Amongst patients with complete remission following $H$. pylori cure, relapse rates were $0 \%$ for high-grade MALT lymphoma after a median follow-up of more than $5 \mathrm{yr}$. This is one of the first studies to suggest that H. pylori eradication may offer a treatment option not only for low grade MALToma but also for early-stage H. pylori-positive gastric DLBCL (MALT).

\section{Uninvestigated Dyspepsia}

The test-and-treat strategy provides an evidence-based management strategy for patients with uninvestigated dyspepsia who are under the age of $55 \mathrm{yr}$ and have no alarm features. For a detailed discussion of the role of $H$. pylori eradication in the management of uninvestigated dyspepsia, the reader is referred to the American College of Gastroenterology's recently published Practice Guideline on the Management of Dyspepsia (15). 


\section{WHAT ARE THE AREAS OF CONTROVERSY FOR WHICH THERE MIGHT BE BENEFIT OF ERADICATING H. PYLORI INFECTION?}

- There is evidence to suggest that a small but significant subgroup of patients with functional dyspepsia will experience clinical benefit following $\mathrm{H}$. pylori eradication.

- There is no clear evidence to support that eradicating H. pylori consistently worsens or improves GERD symptoms. Treatment of $\mathrm{H}$. pylori should not be withheld related to concerns of creating or worsening GERD.

- H. pylori and NSAIDs are independent risk factors for the development of PUD. Therefore, regardless of whether or not a patient is taking an NSAID, all patients with a peptic ulcer should be tested and when infected, treated for $\mathrm{H}$. pylori.

- The available data support an association between $\mathrm{H}$. pylori infection and iron deficiency but do not prove cause and effect.

- Though there is some evidence to suggest that curing $\mathrm{H}$. pylori may prevent progression of intestinal metaplasia to gastric adenocarcinoma, there is no definitive populationbased data to suggest that $\mathrm{H}$. pylori eradication reduces the incidence of gastric adenocarcinoma. Pursuing $\mathrm{H}$. pylori in patients at increased risk for gastric cancer should be individualized taking into consideration comorbid illness, which might have bearing on the benefits offered by treatment, and patient preferences.

\section{Functional Dyspepsia (FD)}

Whether eradicating $H$. pylori infection is of clinical and economic benefit in patients with dyspeptic symptoms who have undergone a negative structural evaluation remains controversial. Whereas some studies observed a beneficial effect (16-19), others have failed to confirm such benefits (20-24). The most recent meta-analyses and systematic reviews have reported that eradication of $H$. pylori infection offers a small but statistically significant clinical benefit (therapeutic gain of $H$. pylori eradication over placebo $=8 \%, \mathrm{NNT}=15$, RR of remaining symptomatic 0.91 [95\% CI $0.86-0.95]$ ]) and may be cost-effective in FD $(25,26)$.

Eradicating H. pylori in patients with FD may offer benefits beyond symptom improvement. Studies have reported that peptic ulcers develop in $1-14 \%$ of patients with FD when followed over extended periods (16, 27-29). A placebocontrolled study from Taiwan found that $H$. pylori eradication reduced the $1 \mathrm{yr}$ incidence of peptic ulcer in patients with ulcer-like functional dyspepsia but not in those with dysmotility-like or unclassifiable FD (28). No such data from the United States are currently available.

With these thoughts in mind, the decision of whether to test for and treat $H$. pylori in FD should be individualized taking into consideration patient concerns as well as the presence of risk factors for PUD (age, NSAID use) (29) and gastric malignancy (ethnic background, family history of gastric malignancy).

\section{Gastroesophageal Reflux Disease (GERD)}

Despite a large number of studies that have addressed this issue, the relationship between $H$. pylori infection and GERD remains incompletely defined. It is known that $H$. pylori infection results in different levels of severity and patterns of gastric inflammation in different individuals. This in turn can lead to varied effects on gastric acid secretion. For example, it has been proposed that patients with antral predominant gastritis, the phenotype most commonly encountered in the United States, exhibit increased acid secretion and are at increased risk of developing duodenal ulcer. On the other hand, those with corpus-predominant or pangastritis tend toward decreased acid secretion and a greater risk of developing gastric cancer (30). As such, eradication of this infection can be associated with a wide spectrum of effects on gastric acid secretion. Whether a patient has abnormal lower esophageal sphincter function or esophageal clearance mechanisms, which would predispose to a greater risk of GERD, undoubtedly also affects outcomes. In this way, one can envision scenarios where eradication of $H$. pylori infection could be associated with worsening, no change, or improvement in GERD. A recent study found that antral predominant gastritis was the most common $\mathrm{H}$. pylori associated phenotype in functional dyspepsia patients from western countries and that eradication therapy in this subgroup of patients led to overall improvements in heartburn and regurgitation at $1 \mathrm{yr}$ of follow-up (31).

Some investigators have suggested that $H$. pylori status is inversely related to the likelihood of suffering with GERD (32). Unfortunately, the heterogeneity of the available data makes it difficult to arrive at a confident conclusion on this matter. A recent systematic review pointed out that geographical location of the studies contributes to the confusion, as GERD patients from the Far East tended to have a lower prevalence of $H$. pylori than patients from Europe or North America (33).

Regarding the issue of whether eradication of $H$. pylori infection may provoke or worsen GERD, a recent systematic review by Raghunath et al. including 27 studies concluded that the available evidence does not support an association between $H$. pylori eradication and the development of reflux esophagitis or worsening of heartburn in patients with a duodenal ulcer (34). Perhaps more relevant to North America, Laine and colleagues performed a post hoc analysis of 8 double-blind, prospective U.S. trials of $H$. pylori therapy for patients with active DU or a history of DU to quantify the development of GERD symptoms in patients without a prior history of symptomatic GERD or esophagitis (35). They assessed whether GERD symptoms worsened in patients with prior symptomatic GERD. Their analysis found no difference in the likelihood of developing new GERD symptoms or esophagitis in individuals cured of $H$. pylori infection compared to those with persistent infection. Further, they found that $H$. pylori eradication was not associated with a worsening of symptoms in those with preexisting GERD. Recent evidence from 
North America and Europe suggests that esophageal acid exposure, the severity of erosive esophagitis, and efficacy of proton pump inhibitor therapy is similar in GERD patients with and without $H$. pylori infection (36-38).

There is no clear evidence to support that a test-and-treat strategy for $H$. pylori consistently worsens or improves GERD symptoms. Therefore, it is reasonable to conclude that therapy for $H$. pylori should not be withheld related to concerns of creating or worsening GERD.

\section{Persons Using Nonsteroidal Antiinflammatory Drugs (NSAIDs) or Aspirin}

The interaction between $H$. pylori infection and NSAIDs in the pathogenesis of PUD remains controversial. Studies attempting to clarify this interaction have yielded conflicting results (39-44). The discordant results can, in part, be explained by differences in study methodology, outcome measures, definitions of ulcer, and patient populations. It is also important to realize that there may be differences in clinical outcomes based upon whether a patient has or has not previously taken NSAIDs and whether one is contemplating primary or secondary prophylaxis (40).

From a practical standpoint, the clinician is interested in knowing whether testing for and treating $H$. pylori in patients taking an NSAID will reduce the risk of developing ulcers or more importantly, ulcer complications. A metaanalysis, which included data from 25 observational studies, demonstrated that both $H$. pylori infection and nonselective NSAID use are independent risk factors for the development of peptic ulcer and ulcer bleeding. Moreover, this meta-analysis also suggested that these risk factors are at least additive and possibly synergistic for the development of peptic ulcer and ulcer bleeding (41). In another recent meta-analysis of five studies including 939 patients, H. $p y$ lori eradication was associated with a reduced incidence of peptic ulcer in patients taking NSAIDs (OR 0.43, 95\% CI 0.20-0.93). Subanalyses demonstrated that risk reduction was evident in NSAID-naïve individuals (OR 0.26, 95\% CI $0.14-0.49)$ but not for those previously taking NSAIDs (OR 0.95, 95\% CI 0.53-1.72) (42). While H. pylori eradication may reduce the risk of PUD, it does not eliminate the risk of ulcer development or complications in those using an NSAID.

At present, it seems reasonable to recommend that any patient with an ulcer should be tested for $H$. pylori regardless of whether or not he/she is taking an NSAID or aspirin (44). There are some data to support the identification and treatment of H. pylori in NSAID-naïve patients who are to be treated with an NSAID (45). To date, similar data demonstrating the utility of H. pylori eradication in aspirin-naïve patients starting aspirin are not available. In patients already taking an NSAID, H. pylori eradication appears to be less effective than PPI therapy in reducing the risk of peptic ulcer recurrence or ulcer bleeding (6 month rate of recurrent bleeding $18.8 \%$ for $H$. pylori therapy $v s 4.4 \%$ for PPI therapy,
$P=0.005)$. On the other hand, there is evidence to suggest that recurrent ulcer bleeding in persons using low-dose aspirin is similar 6 months after $H$. pylori eradication or with PPI therapy (6 month rate of recurrent bleeding 1.9\% for $H$. pylori therapy vs $0.9 \%$ for PPI therapy, $P=\mathrm{NS}$ ) (46). For patients with a history of an ulcer complication who require subsequent therapy with an NSAID or aspirin, H. pylori eradication alone may not be a sufficient risk reduction strategy. Co-therapy with a PPI in such patients at high risk for recurrence of an ulcer complication has been recommended (44).

\section{Iron Deficiency Anemia}

A number of studies have suggested a potential association between unexplained iron deficiency anemia and $H$. pylori infection. The explanation most commonly offered for this relationship is based upon the development of $H$. pyloriassociated chronic pangastritis with resultant achlorhydria and reduced ascorbic acid secretion leading to reduced intestinal iron absorption. Other potential explanations for an association between iron deficiency and $H$. pylori include occult blood loss from erosive gastritis and sequestration and utilization of iron by the organism (47).

Recent large studies from North America have reported H. pylori infection was an independent risk factor for iron deficiency anemia in 688 school-aged children from Alaska (48) and 7,462 children, adolescents, and adults from the United States (49). In the study by Cardenas and colleagues, H. pylori infection was associated with an increased risk of iron deficiency anemia (OR 2.6, 95\% CI 1.5-4.6). There is emerging evidence to suggest that eradication of $H$. pylori can improve iron deficiency anemia (50-52) though this remains controversial. A recent unblinded study in 219 H. pyloriinfected children (7-11 yr) with pretreatment iron deficiency from Alaska found no difference in the likelihood of iron deficiency or anemia at 2 months or 14 months following a 6-wk course of oral iron and antibiotics or no antibiotics (53).

The available data support an association between $H$. pylori infection and iron deficiency but do not prove cause and effect. Further properly designed, adequately powered randomized trials are needed to assess whether $H$. pylori eradication offers benefit to patients with unexplained iron deficiency anemia.

\section{Prevention of Gastric Cancer}

Whether curing $H$. pylori infection can reduce the risk of developing gastric adenocarcinoma remains unknown (54). However, there have been a number of recent studies that have evaluated the effect of $H$. pylori eradication on surrogate outcomes such as the severity and distribution of gastritis and gastric preneoplastic lesions (multifocal atrophic gastritis, intestinal metaplasia, or dysplasia) (55-58). In a randomized, placebo-controlled trial, Leung et al. followed $435 \mathrm{H}$. pylori-infected patients for $5 \mathrm{yr}$ after a course of anti-H. pylori therapy or placebo. In a multiple logistic regression analysis, 
they observed that persistent $H$. pylori infection (OR 2.13, 95\% CI 1.41-3.24), age >45 yr (OR 1.92, 95\% CI 1.183.11 ), alcohol consumption (OR 1.67, 95\% CI 1.07-2.62), and drinking local well water (OR 1.74, 95\% CI 1.13-2.67) were independent risk factors associated with intestinal metaplasia progression. They concluded that $H$. pylori eradication was protective against progression of premalignant gastric lesions in their Chinese population study (55). In a study from Columbia, 795 adults with preneoplastic gastric lesions were randomized to anti-H. pylori therapy or antioxidants and were followed with serial endoscopies over 12 yr. Multivariate analysis revealed a significant regression in histopathology score as a function of the square of time without $H$. pylori infection. Further, patients treated for $H$. pylori were $13.7 \%$ less likely to experience progression of preneoplastic gastric lesions (57). Wong et al. recruited 1,630 asymptomatic H. pylori-infected subjects in a high-risk region of China, and randomly allocated them to $H$. pylori therapy or placebo, after which they were followed for $7.5 \mathrm{yr}$. They reported that gastric cancer developed in 18 cases. There was an absolute reduction in gastric cancer incidence in subjects who received $H$. pylori eradication therapy when compared with placebo, which was not statistically significant (37\% reduction, $P=0.33$ ). However, in a subgroup of $H$. pylori carriers without precancerous lesions at index endoscopy, the incidence of gastric cancer was significantly lower in subjects receiving eradication therapy than in those receiving placebo $(P=0.02)$. This study supports the possibility that $H$. pylori eradication may reduce the risk of developing gastric cancer in individuals without precancerous lesions from high-risk populations (58). No such evidence is available from regions of the world where gastric cancer is rare, such as the United States.

A recent international working group reviewed the literature addressing this topic. The majority of the scientific task force favored testing and treating $H$. pylori in first-degree relatives of gastric cancer patients. The task force also endorsed the evaluation of the chemopreventive benefits for gastric malignancy with a more general screen and treat strategy in populations with a high incidence of $H$. pylori-associated diseases (54).

\section{DIAGNOSIS OF H. PYLORI INFECTION}

- Testing for H. pylori should only be performed if the clinician plans to offer treatment for positive results.

- Deciding which test to use in which situation relies heavily upon whether a patient requires evaluation with upper endoscopy and an understanding of the strengths, weaknesses, and costs of the individual tests.

The methods of diagnostic testing for $H$. pylori can be divided into those that do and those that do not require endoscopy. Table 2 provides a list of the available diagnostic tests for $H$. pylori. There is no single test that can be considered the gold standard for the diagnosis of $H$. pylori. Rather, the most appropriate test for any specific situation will be influenced by the clinical circumstances, the pretest probability of infection, as well as the availability and costs of the individual diagnostic tests.

Table 2. Diagnostic Testing for Helicobacter pylori

\begin{tabular}{|c|c|c|}
\hline Endoscopic Testing & Advantages & Disadvantages \\
\hline *1. Histology & Excellent sensitivity and specificity & $\begin{array}{l}\text { Expensive and requires infrastructure and } \\
\text { trained personnel }\end{array}$ \\
\hline *2. Rapid urease testing & $\begin{array}{l}\text { Inexpensive and provides rapid results. Excellent } \\
\text { specificity and very good sensitivity in properly } \\
\text { selected patients }\end{array}$ & $\begin{array}{l}\text { Sensitivity significantly reduced in the } \\
\text { posttreatment setting }\end{array}$ \\
\hline *3. Culture & $\begin{array}{l}\text { Excellent specificity. Allows determination of } \\
\text { antibiotic sensitivities }\end{array}$ & $\begin{array}{l}\text { Expensive, difficult to perform, and not widely } \\
\text { available. Only marginal sensitivity }\end{array}$ \\
\hline *4. Polymerase chain reaction & $\begin{array}{l}\text { Excellent sensitivity and specificity. Allows } \\
\text { determination of antibiotic sensitivities }\end{array}$ & $\begin{array}{l}\text { Methodology not standardized across } \\
\text { laboratories and not widely available }\end{array}$ \\
\hline
\end{tabular}

\begin{tabular}{|c|c|c|}
\hline Nonendoscopic Testing & Advantages & Disadvantages \\
\hline $\begin{array}{l}\text { 1. Antibody testing (quantitative } \\
\text { and qualitative) }\end{array}$ & Inexpensive, widely available, very good NPV & $\begin{array}{l}\text { PPV dependent upon background H. pylori } \\
\text { prevalence. Not recommended after H. pylori } \\
\text { therapy }\end{array}$ \\
\hline $\begin{array}{l}\text { *2. Urea breath tests }\left({ }^{13} \mathrm{C} \text { and }\right. \\
\left.{ }^{14} \mathrm{C}\right)\end{array}$ & $\begin{array}{l}\text { Identifies active } H \text {. pylori infection. Excellent PPV } \\
\text { and NPV regardless of } H \text {. pylori prevalence. } \\
\text { Useful before and after } \\
\text { H. pylori therapy }\end{array}$ & $\begin{array}{l}\text { Reimbursement and availability remain } \\
\text { inconsistent }\end{array}$ \\
\hline *3. Fecal antigen test & $\begin{array}{l}\text { Identifies active } H \text {. pylori infection. Excellent } \\
\text { positive and negative predictive values regardless } \\
\text { of } H \text {. pylori prevalence. Useful before and after } H \text {. } \\
\text { pylori therapy }\end{array}$ & $\begin{array}{l}\text { Polyclonal test less well validated than the UBT } \\
\text { in the posttreatment setting. Monoclonal test } \\
\text { appears reliable before and after antibiotic } \\
\text { therapy. Unpleasantness associated with } \\
\text { collecting stool }\end{array}$ \\
\hline
\end{tabular}

\footnotetext{
${ }^{*}$ The sensitivity of all endoscopic and nonendoscopic tests that identify active $H$. pylori infection is reduced by the recent use of PPIs, bismuth, or antibiotics $\mathrm{PPI}=$ proton pump inhibitor; PPV = positive predictive value; NPV = negative predictive value; $\mathrm{UBT}=$ urea breath test
} 


\section{Endoscopic Diagnostic Tests}

- In patients who have not been on a PPI within 1-2 wk or an antibiotic or bismuth within 4 wk of endoscopy, the rapid urease test (RUT) provides an accurate, inexpensive means of identifying $\mathrm{H}$. pylori.

- For patients who have been taking a PPI, antibiotics, or bismuth, endoscopic testing for $\mathrm{H}$. pylori should include biopsies from the gastric body and antrum for histology with or without rapid urease testing.

- Though culture or polymerase chain reaction (PCR) are the primary means by which antibiotic sensitivities can be determined, neither is widely available for clinical use in the United States and therefore, cannot be routinely recommended.

There are presently four biopsy-based diagnostic methods for H. pylori infection. These include the RUT, histology, culture, and PCR.

\section{Rapid Urease Testing}

The RUT identifies active $H$. pylori infection through the organism's urease activity. Gastric biopsies are obtained and placed into an agar gel or on a reaction strip containing urea, a buffer, and a $\mathrm{pH}$-sensitive indicator. In the presence of H. pylori's urease, urea is metabolized to ammonia and bicarbonate leading to a $\mathrm{pH}$ increase in the microenvironment of the organism. A change in color of the $\mathrm{pH}$ sensitive indicator signifies the presence of active infection. Commercially available kits yield results in 1-24 h.

There are a number of commercially available RUT kits in the United States including the CLOtest, $H p$ Fast, HUT-test, Pronto Dry, and Pyloritek with overall pretreatment sensitivities of $>90 \%$ and specificities of $>95 \%(59,60)$. Though the overall performance of the different tests is comparable, there are some practical differences between the individual tests (61).

Medications that reduce the density and/or urease activity of $H$. pylori, such as bismuth-containing compounds, antibiotics, or PPIs, can decrease the sensitivity of the RUT by up to $25 \%$ (59). Though controversial, acute ulcer bleeding at the time of testing may decrease the sensitivity and negative predictive value of the RUT (62-66). As a result of the patchy distribution of $H$. pylori infection after antibiotics or PPIs, it is recommended that biopsies for the RUT be obtained from two sites, the body at the gastric anglularis and greater curvature of the antrum (67). The simplicity, low cost, and relatively rapid results make the RUT a practical and costeffective means of testing for $H$. pylori in patients not taking antibiotics, bismuth, or PPIs who require upper endoscopy. Unfortunately, the usefulness of the RUT in routine clinical practice has been compromised by the widespread use of PPIs as an empiric treatment for upper GI symptoms. As such, the RUT can rarely be used as a sole means of identifying H. pylori infection. More commonly, the RUT is combined with other endoscopic or nonendoscopic modalities to establish the presence or absence of this infection. No studies have been performed to define the duration of a PPI's deleterious effects on the sensitivity of the RUT. Data with the urea breath test (UBT) suggest that PPI therapy can cause false-negative test results for $1-2$ wk $(68,69)$. As the UBT and RUT rely upon the identification of H. pylori's urease activity, it is reasonable to suggest that PPIs should be withheld for 1-2 wk before performance of the RUT. In situations where a patient has not taken a PPI for a period of 1-2 wk before their procedure, the sensitivity of the RUT is likely sufficient to justify its use as a single test for $H$. pylori.

\section{Histology}

Histology has been considered by some to be the gold standard for detection of H. pylori (70). Unfortunately, histology is an imperfect gold standard as the detection of $H$. pylori relies upon a number of issues including the site, number, and size of gastric biopsies, method of staining, and the level of experience of the examining pathologist (70). A significant advantage of histology over other diagnostic methods is the ability to evaluate for pathologic changes associated with $H$. pylori infection such as inflammation, atrophy, intestinal metaplasia, and malignancy (71). In fact, some have argued that type B chronic gastritis (nonatrophic diffuse antral gastritis or atrophic pangastritis) can be used as a surrogate marker for the infection when organisms are not identified (72). Certainly the absence of chronic gastritis is a potent negative predictor for the presence of $H$. pylori infection.

As the prevalence and density of $H$. pylori varies throughout the stomach, particularly in the face of medications that may reduce the density of $H$. pylori, multiple biopsies are needed for accurate diagnosis. It is therefore recommended that a minimum of three biopsies be obtained, one from the anglularis, one from the greater curvature of the corpus, and one from the greater curvature of the antrum, to maximize the diagnostic yield of histology (70). A recent study found that the addition of corpus biopsies to antral biopsies increased the detection of $H$. pylori infection by $\sim 10 \%$ when compared with antral biopsies alone (73). Similar to the RUT, the sensitivity of histology is significantly affected by the use of medications such as bismuth, antibiotics, and PPIs (67). Although widely available and capable of achieving sensitivity and specificity of $>95 \%$, the cost and need for properly trained personnel are limitations of histology in clinical practice.

\section{Culture}

Culture is another highly specific method for identifying active H. pylori infection. Conceptually, culture is attractive because it not only provides a means by which to identify infection, but also allows characterization of antimicrobial sensitivities (74). Unfortunately, culture is not as sensitive as RUT or histology $(75,76)$. Furthermore, culturing techniques for $H$. pylori are demanding and costly and as a consequence, only available in a limited number of clinical laboratories. Nonculture-based means of determining antibiotic 
resistance are being developed but have not been adequately standardized and are not widely available.

\section{Polymerase Chain Reaction}

PCR is a DNA amplification technique that utilizes the rapid production of multiple copies of a target DNA sequence to identify $H$. pylori. This testing method is highly specific and may be more sensitive than other biopsy-based diagnostic techniques. A recent study found that PCR was able to detect $H$. pylori in approximately $20 \%$ of gastric biopsies with chronic gastritis but no identifiable organisms by histology (77). PCR also provides a means of identifying mutations associated with antimicrobial resistance (78-80). Although presently restricted to the research arena, this method may some day provide a practical, reproducible method for antibiotic sensitivity testing, organism typing, and organism virulence testing (81).

\section{Nonendoscopic Diagnostic Tests}

- Antibody testing is inexpensive and widely available but poor PPV in populations with a low prevalence of $\mathrm{H}$. pylori infection limits its usefulness in clinical practice.

- The UBTs and fecal antigen tests provide reliable means of identifying active $\mathrm{H}$. pylori infection before antibiotic therapy.

- The UBT is the most reliable nonendoscopic test to document eradication of $\mathrm{H}$. pylori infection.

- The monclonal fecal antigen test provides another nonendoscopic means of establishing $\mathrm{H}$. pylori cure after antibiotic treatment.

- Testing to prove H. pylori eradication appears to be most accurate if performed at least 4 wk after the completion of antibiotic therapy.

There are currently three nonendoscopic diagnostic testing methods for $H$. pylori infection. Antibody testing identifies an immunological reaction to the infection while the nonendoscopic urease tests and fecal antigen test identify the presence of active $H$. pylori infection.

\section{Antibody Tests}

Antibody testing relies upon the detection of $\operatorname{IgG}$ antibodies specific to H. pylori in serum, whole blood, or urine. IgG antibodies to $H$. pylori typically become present approximately 21 days after infection and can remain present long after eradication (82). Antibodies to H. pylori can be quantitatively assessed using enzyme-linked immunosorbent assay (ELISA) and latex agglutination techniques or qualitatively assessed using office-based kits. The advantages of the antibody tests are their low cost, widespread availability, and rapid results. Unfortunately, several factors limit the usefulness of antibody testing in clinical practice. A meta-analysis evaluated the performance characteristics of several commercially available quantitative serological assays and found their overall sensitivity and specificity to be $85 \%$ and $79 \%$, respectively, with no differences between the different assays

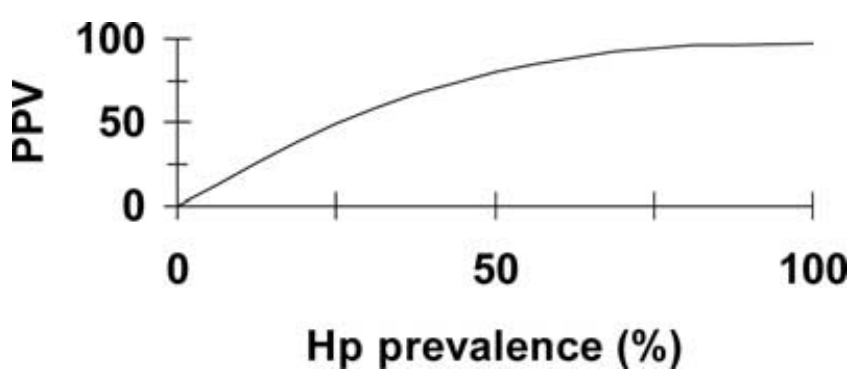

Figure 1. Effect of $H$. pylori prevalence on the positive predictive value (PPV) of antibody testing (where sensitivity $=85 \%$ and specificity $=79 \%)(144)$.

(83). Three of the qualitative whole blood antibody kits were directly compared in another study demonstrating sensitivities ranging from $76 \%$ to $84 \%$ and specificities of $79-90 \%$ (84). In general, performance characteristics for the qualitative office-based tests have been more variable than those yielded by the quantitative tests. It is very important to understand that the PPV of antibody testing is greatly influenced by the prevalence of H. pylori infection (85) (Fig. 1). This issue will be further discussed in the section addressing the use of diagnostic testing in clinical practice. Further, antibody tests developed using antigens from one region of the world may not perform well when applied to patients in another part of the world suggesting that local validation may be necessary $(75,86)$. Finally, antibody tests are of little benefit in documenting eradication as results can remain positive for years following successful cure of the infection (82).

\section{Urea Breath Tests}

The UBT, like the RUT, identifies active $H$. pylori infection by way of the organism's urease activity. In the presence of $H$. pylori, the ingestion of urea, labeled with either the nonradioactive isotope ${ }^{13} \mathrm{C}$ or the radioactive isotope ${ }^{14} \mathrm{C}$, results in production of labeled $\mathrm{CO}_{2}$, which can be quantitated in expired breath (87-90). Although the amount of radiation in the ${ }^{14} \mathrm{C}$ UBT is less than daily background radiation exposure (88), the ${ }^{13} \mathrm{C}$ test is preferred in children and pregnant females (87). Overall, the performance characteristics of both tests are similar with sensitivity and specificity typically exceeding $95 \%$ in most studies $(87,88)$. Test reproducibility has been found to be excellent (89). The UBT also provides an accurate means of posttreatment testing (90-93). Most tests utilize a citrate test meal $(50-75 \mathrm{mg})$, which is administered before the labeled urea (87). A urease blood test, which relies upon the detection of labeled bicarbonate in a blood sample, also reliably identifies active $H$. pylori infection before and after treatment $(94,95)$. As the nonendoscopic urease tests rely upon the identification of $\mathrm{H}$. pylori's robust urease activity, test sensitivity is decreased by medications that reduce organism density or urease activity, including bismuth containing compounds, antibiotics, and PPIs. It is currently recommended that bismuth and antibiotics be withheld for at least 28 days and a PPI for 7-14 days prior to the UBT (68, 
Table 3. Performance Characteristics of the Fecal Antigen Test (95)

\begin{tabular}{crccccc}
\hline & \# Studies / & & & & \\
& \# Patients & Sensitivity & Specificity & PPV & NPV \\
\hline Pretreatment & & & & & \\
Polyclonol & $89 / 10,858$ & 91 & 93 & 92 & 87 \\
Monoclonol & $8 / 1,399$ & 96 & 97 & 96 & 97 \\
Posttreatment & & & & & \\
Polyclonol & $39 / 3,147$ & 86 & 92 & 76 & 93 \\
Monoclonol & $6 / 418$ & 95 & 97 & 91 & 98 \\
\hline
\end{tabular}

$\mathrm{PPV}=$ positive predictive value; $\mathrm{NPV}=$ negative predictive value

$69,96)$. It is controversial whether $\mathrm{H}_{2} \mathrm{RAs}$ affect the sensitivity of the UBT (97-99) though many laboratories recommend withholding these drugs for $24-48 \mathrm{~h}$ before the UBT. Antacids do not appear to affect the accuracy of the UBT (100). Aside from the issues just discussed, other factors affecting the acceptance of the UBT in clinical practice include the need for infrastructure to perform the test, the need for a patient to attend an additional outpatient visit to undergo the test, and cost. At current levels of reimbursement in the United States, the UBT is more costly than the antibody tests or fecal antigen test. The expense of the UBT is largely driven by equipment costs and the cost of labeled urea. UBTs using lower dose ${ }^{13} \mathrm{C}$, which have recently been found to yield excellent performance characteristics, may in part address this issue (101).

\section{Fecal Antigen Test}

The fecal antigen test (FAT) identifies $H$. pylori antigen in the stool by enzyme immunoassay with the use of polyclonal anti-H. pylori antibody. Recently, a stool test utilizing a monoclonal anti-H. pylori antibody has been evaluated $(102,103)$. As both tests detect bacterial antigen(s) suggestive of ongoing infection, they can be used to screen for infection and as a means of establishing cure following therapy. A recent systematic review (102) reported performance characteristics of the FAT before and after eradication therapy (Table 3). While this analysis demonstrated excellent sensitivity, specificity, positive and negative predictive values for the polyclonal test before treatment, sensitivity and PPV were less satisfactory after treatment. On the other hand, the monoclonal test yielded sensitivity, specificity, and predictive values greater than $90 \%$ before and after treatment. The precise explanations for the differences in accuracy between the polyclonal and monoclonal tests remain unclear but may have to do with the need for intraperitoneal injection of $H$. pylori antigens into rabbits to produce antibodies for the polyclonal assay (102). The FAT has been approved by the U.S. Food and Drug Administration and endorsed by the European "Maastricht 2-2000 Consensus Report" as an alternative means of establishing H. pylori cure to urea breath testing (104). Recent studies indicate that the FAT may be effective in confirming eradication as early as 14 days after treatment $(105,106)$. However, there is evidence to suggest that the FAT should be done more than $4 \mathrm{wk}$ and perhaps as long as $8-12 \mathrm{wk}$ after treatment of $H$. pylori (102).
When testing for H. pylori in populations with a low pretest probability of infection, the FAT provides greater accuracy than serologic testing with only a modest increase in incremental costs (107). Similar to the UBT, the sensitivity of the FAT is affected by the recent use of bismuth compounds, antibiotics, and PPIs $(108,109)$. Recent studies also suggest that the specificity of the FAT is reduced in the setting of bleeding PUD and, for this reason, should not be the sole diagnostic test employed in this setting (110-113). Although the FAT is simple to administer and perform, issues slowing its widespread use include the unpleasantness of handling and storing stool, limited availability, and variable state-tostate reimbursement. The development of in-office stool tests is under way and may improve upon some of the practical limitations of the currently available tests (102). At present, in-office tests have not been adequately validated in clinical trials.

Based upon the available data, it is reasonable to conclude that the FAT can be used interchangeably with the UBT to identify $H$. pylori before antibiotic therapy. The polyclonal FAT has been less well validated than the UBT in the posttreatment setting. Compared with the polyclonal test, the monoclonal FAT appears to provide a more reliable means of proving $H$. pylori eradication.

\section{H. PYLORI TESTING IN CLINICAL PRACTICE}

\section{Testing When There Is a Need for Endoscopy}

If endoscopy is necessary based upon the patient's clinical presentation, biopsy-based endoscopic tests are most appropriate. Provided the patient has not been on recent bismuth, antibiotics, or a PPI, the RUT offers the desirable combination of accuracy and low cost. If there are mucosal abnormalities identified at the time of endoscopy, which require further histologic evaluation, biopsies should be obtained for histology. Unfortunately, most patients referred for upper endoscopy are taking acid-suppressive agents such as a PPI or $\mathrm{H}_{2} \mathrm{RA}$ or have recently received drugs that can suppress $H$. pylori (antibiotics or bismuth). In such patients, it is appropriate to obtain biopsies for histology with or without RUT or plan testing with a UBT or FAT at a later date after withholding the offending agents for an appropriate period of time.

In the setting of an active ulcer bleed, there are case series and cohort studies that suggest that the sensitivity of the RUT and, to a lesser extent, histology may be reduced (62, $63,114,115)$. These studies suggest that although positive results reliably identify the presence of $H$. pylori infection, the likelihood of false-negative results may be increased in the setting of acute upper gastrointestinal bleeding. A recent prospective cohort study from the United States did not confirm findings from previous studies (65). In this study, 61 patients with variceal hemorrhage underwent biopsy-based H. pylori testing during an initial endoscopy for acute bleeding and again 1 month later. The sensitivities of RUT and histology performed during acute bleeding and 1 month later were not significantly different. However, it is notable that 
the sensitivity of the RUT in this study was relatively low at both time points (initial RUT $=79 \%$, follow-up RUT $=$ $71 \%$ ). Regardless of which results one chooses to believe, it is important to emphasize that a positive RUT indicates the presence of active $H$. pylori infection. On the other hand, a negative RUT and/or histology in the setting of acute upper GI bleeding should be confirmed with another test. An antibody test provides a reasonably sensitive nonendoscopic testing option. In this setting, because the pretest probability of H. pylori infection is high in a patient with an ulcer, the PPV of an antibody test is reasonably high (Fig. 1). Alternatively, a patient can undergo a UBT or FAT at a later date after withholding medications that can negatively affect the sensitivity of these tests for an appropriate period of time. Recent work suggests that engaging in such a practice significantly increases the detection of $H$. pylori infection in patients with recent ulcer bleeding. A recent retrospective study from Spain found that 57 of $72(79 \%)$ patients with ulcer bleeding and no evidence of $H$. pylori on emergency endoscopy had a positive "delayed" UBT (116).

\section{Testing in Patients With Uninvestigated Dyspepsia}

Primary care providers are frequently asked to evaluate and treat patients with uninvestigated dyspepsia. The testand-treat strategy for $H$. pylori has been endorsed for the management of uninvestigated dyspepsia by a number of organizations, including the American Gastroenterological Association (117) and the American College of Gastroenterology (15). For a detailed discussion regarding $H$. pylori testing in patients with uninvestigated dyspepsia, the reader is referred to these recent publications $(15,117)$. Both documents emphasize that in regions where the prevalence of $H$. pylori infection is high, such as urban areas or communities with large immigrant populations, the PPV of antibody testing is reasonably good and therefore provides an acceptable means of screening for $H$. pylori infection. However, in regions where $H$. pylori prevalence is low, the PPV of antibody testing is poor (85). From a pragmatic standpoint, this means that if a physician practices in a community with an $H$. pylori prevalence of less than $\sim 20 \%$, as is the case in much of the United States, though a negative antibody test suggests the absence of infection, a positive test is no better than a coin toss in predicting the presence of active infection (Fig. 1). As such, in low prevalence populations, antibody tests should be avoided altogether or positive results should be confirmed with a test that identifies active infection such as the UBT or FAT prior to initiating eradication therapy $(117,118)$.

\section{Testing to Prove Eradication After Antibiotic Therapy}

In an ideal world, all patients treated for $H$. pylori infection would undergo testing to prove eradication of the infection. Unfortunately, universal posttreatment testing is neither practical nor cost-effective. Since publication of the last ACG guideline on $H$. pylori infection (3), the accepted indications for testing to prove eradication after antibiotic therapy, largely based upon expert consensus, have broadened to include:
- Any patient with an $H$. pylori-associated ulcer.

- Individuals with persistent dyspeptic symptoms despite the test-and-treat strategy.

- Those with $H$. pylori-associated MALT lymphoma.

- Individuals who have undergone resection of early gastric cancer.

When confirmation of eradication is necessary, testing should generally be performed no sooner than 4 wk after the completion of treatment. Because of its high cost, endoscopic tests should only be used if endoscopy is clinically indicated for other reasons. If testing to prove eradication were performed in the setting of endoscopy, most would advocate using histology or the combination of histology and RUT as RUT alone has reduced sensitivity in the posttreatment setting (119). When endoscopic follow-up is unnecessary, testing to prove eradication of $H$. pylori infection is best accomplished with the UBT. The FAT provides an alternative means of establishing eradication though, as has already been discussed, the timing and reliability of this test have not been as clearly demonstrated as for the UBT. Because antibody tests can remain positive for prolonged periods following successful cure of $H$. pylori infection, they should be avoided in the posttreatment setting. If antibody testing is performed in the posttreatment setting, only a negative result is reliable. A positive result should be confirmed with a UBT or FAT before offering antibiotic therapy for presumed persistent infection.

\section{TREATMENT OF H. PYLORI INFECTION}

\section{Primary Treatment of $\mathbf{H}$. pylori Infection}

- In the United States, the recommended primary therapies for H. pylori infection include: a PPI, clarithromycin, and amoxicillin, or metronidazole (clarithromycin-based triple therapy) for 14 days or a PPI or $\mathrm{H}_{2} \mathrm{RA}$, bismuth, metronidazole, and tetracycline (bismuth quadruple therapy) for 10-14 days.

- Sequential therapy consisting of a PPI and amoxicillin for 5 days followed by a PPI, clarithromycin, and tinidazole for an additional 5 days may provide an alternative to clarithromycin-based triple or bismuth quadruple therapy but requires validation within the United States before it can be recommended as a first-line therapy.

The first course of therapy offers the greatest likelihood of eradicating $H$. pylori infection. Subsequent treatment trials, particularly if the same antibiotics are utilized or if the patient has been previously exposed to any antibiotics contained in the treatment regimen, are less likely to achieve a successful outcome. As such, it is important to only use treatment regimens for which there is evidence of proven effectiveness (120).

In the United States, the recommended primary therapies for H. pylori infection include: a PPI, clarithromycin, and amoxicillin or metronidazole (clarithromycin-based triple therapy) or a PPI or $\mathrm{H}_{2} \mathrm{RA}$, bismuth, metronidazole, and tetra- 
Table 4. First-Line Regimens for Helicobacter pylori Eradication

\begin{tabular}{|c|c|c|c|}
\hline Regimen & Duration & Eradication Rates & Comments \\
\hline $\begin{array}{l}\text { Standard dose PPI b.i.d. (esomeprazole is q.d.), } \\
\text { clarithromycin } 500 \mathrm{mg} \text { b.i.d., amoxicillin } 1,000 \mathrm{mg} \text { b.i.d. }\end{array}$ & $10-14$ & $70-85 \%$ & $\begin{array}{l}\text { Consider in nonpenicillin allergic patients who } \\
\text { have not previously received a macrolide }\end{array}$ \\
\hline $\begin{array}{l}\text { Standard dose PPI b.i.d., clarithromycin } 500 \mathrm{mg} \text { b.i.d. } \\
\text { metronidazole } 500 \mathrm{mg} \text { b.i.d. }\end{array}$ & $10-14$ & $70-85 \%$ & $\begin{array}{l}\text { Consider in penicillin allergic patients who } \\
\text { have not previously received a macrolide or } \\
\text { are unable to tolerate bismuth quadruple } \\
\text { therapy }\end{array}$ \\
\hline
\end{tabular}

Bismuth subsalicylate $525 \mathrm{mg}$ p.o. q.i.d. metronidazole $\quad 10-14 \quad 75-90 \% \quad$ Consider in penicillin allergic patients

$250 \mathrm{mg}$ p.o. q.i.d., tetracycline $500 \mathrm{mg}$ p.o. q.i.d., ranitidine $150 \mathrm{mg}$ p.o. b.i.d. or standard dose

PPI q.d. to b.i.d.

PPI + amoxicillin $1 \mathrm{~g}$ b.i.d. followed by: $\quad 5 \quad>90 \% \quad$ Requires validation in North America

PPI, clarithromycin $500 \mathrm{mg}$, tinidazole $500 \mathrm{mg}$ b.i.d.

5

PPI = proton pump inhibitor; pen = penicillin; p.o. = orally; q.d. = daily; b.i.d. $=$ twice daily; t.i.d. $=$ three times daily; q.i.d. $=$ four times daily

* Standard dosages for PPIs are as follows:

lansoprazole $30 \mathrm{mg}$ p.o., omeprazole $20 \mathrm{mg}$ p.o., pantoprazole $40 \mathrm{mg}$ p.o., rabeprazole $20 \mathrm{mg}$ p.o., esomeprazole $40 \mathrm{mg}$ p.o.

Note: the above recommended treatments are not all FDA approved. The FDA approved regimens are as follows:

1. Bismuth $525 \mathrm{mg}$ q.i.d. + metronidazole $250 \mathrm{mg}$ q.i.d. + tetracycline $500 \mathrm{mg}$ q.i.d. $\times 2 \mathrm{wk}+\mathrm{H}_{2} \mathrm{RA}$ as directed $\times 4$ wk.

2. Lansoprazole $30 \mathrm{mg}$ b.i.d. + clarithromycin $500 \mathrm{mg}$ b.i.d. + amoxicillin $1 \mathrm{~g}$ b.i.d. $\times 10$ days

3. Omeprazole $20 \mathrm{mg}$ b.i.d. + clarithromycin $500 \mathrm{mg}$ b.i.d. + amoxicillin 1 g b.i.d. $\times 10$ days.

4. esomeprazole $40 \mathrm{mg}$ q.d. + clarithromycin $500 \mathrm{mg}$ b.i.d. + amoxicillin $1 \mathrm{~g}$ b.i.d. $\times 10$ days

5. Rabeprazole $20 \mathrm{mg}$ b.i.d. + clarithromycin $500 \mathrm{mg}$ b.i.d. + amoxicillin $1 \mathrm{~g}$ b.i.d. $\times 7$ days.

cycline (bismuth quadruple therapy). Details regarding these regimens can be found in Table 4 . When given at the recommended doses, most recent studies report intention-to-treat (ITT) eradication rates in the range of $70-80 \%(121-124)$. Large randomized trials suggest that the inclusion of amoxicillin or metronidazole yields similar results when combined with a PPI and clarithromycin (125). Though international guidelines have recommended treatment durations of at least 7 days, treatment durations of 10-14 days have typically been employed in the United States (3). A recent large trial from the United States, which evaluated the combination of rabeprazole, clarithromycin, and amoxicillin, found that 7 and 10 days of therapy yielded equivalent eradication rates. The ITT eradication rate for 7 days was $77 \%$ (95\% CI $71-83 \%)$ versus $78 \%$ (95\% CI $72-84 \%$ ) for the 10 -day regimens. This study also reported an eradication rate of $27 \%$ for a 3-day treatment regimen (123). A recent meta-analysis of seven studies involving more than 900 patients found that a 14-day course of clarithromycin triple therapy provided better eradication rates than a 7-day course of therapy (Peto OR 0.62 favors 14 vs 7 days of therapy for eradication of $H$. pylori infection [95\% CI 0.45-0.84]). There was also a trend towards improved efficacy with 10 days of therapy compared with 7 days of therapy, which did not reach statistical significance (126). The superiority of 14-day versus 7-day treatment duration has been confirmed by a recent large randomized single center trial from Italy (127). As a result of the falling eradication rates with clarithromycin-based triple therapy, it is essential to take every opportunity to optimize treatment success. Given the results of this meta-analysis, it seems prudent to recommend a 14-day course of clarithromycin triple therapy, particularly in the United States where eradication rates have typically been $80 \%$ or less with shorter durations of therapy. Treatment durations of less than 7 days are clearly associated with reduced eradication rates and are not recommended. The currently available PPIs perform comparably when used in these regimens $(128,129)$. Data from a recent meta-analysis of 13 studies suggests that b.i.d. dosing of a PPI in clarithromycin-based triple regimens is more effective than q.d. dosing (130). Pretreatment with a PPI prior to a course of $H$. pylori eradication therapy does not appear to adversely influence treatment outcomes (131). Further, it appears that an $\mathrm{H}_{2} \mathrm{RA}$ can be substituted if a patient cannot tolerate a PPI (132).

Bismuth quadruple therapy has been advocated as a primary therapy for $H$. pylori (133). Bismuth quadruple therapy offers eradication rates that are similar to clarithromycin triple therapy. A recent meta-analysis including 5 randomized trials reported ITT and per protocol (PP) eradication rates of $79 \%(95 \%$ CI $74-81 \%)$ and $85 \%$ (95\% CI $81-$ $88 \%$ ) for clarithromycin triple therapy and $80 \%$ (95\% CI $77-84 \%$ ) and $87 \%$ (95\% CI 84-91\%) for bismuth quadruple therapy, respectively (134). Though this regimen has been evaluated with an $\mathrm{H}_{2} \mathrm{RA}$ or PPI, a recent meta-analysis found that quadruple therapy with a PPI provides greater efficacy in patients with metronidazole-resistant $H$. pylori strains (135). A criticism of this regimen involves its complexity (q.i.d. dosing regimen and high pill count) and perceived frequency of side effects. A simplified 14-day b.i.d.dosing regimen recently evaluated by Graham and colleagues in the United States achieved an eradication rate of $92 \%(95 \%$ CI 79-98\%) (136). Another recent study reported comparable eradication rates with a novel triple antibiotic capsule given t.i.d. and a PPI b.i.d. for 10 days (137). Although minor side effects with bismuth-based quadruple therapy occur commonly, the frequency of moderate or severe side effects is no greater than with clarithromycin-based triple therapy (133). 
It seems reasonable to consider a PPI, clarithromycin, and amoxicillin in patients who have not previously received clarithromycin and who are not allergic to penicillin. For patients allergic to penicillin, metronidazole can be substituted for amoxicillin. Bismuth quadruple therapy should be favored in those allergic to penicillin or in those who have previously been treated with a macrolide antibiotic.

Unfortunately, eradication rates yielded by clarithromycinbased triple therapy or bismuth-based quadruple therapy are less than $85 \%$ and may be decreasing. As such, alternative primary therapies are necessary. Several studies from Italy have reported eradication rates exceeding $90 \%$ with a novel sequential therapy consisting of a PPI and amoxicillin for 5 days followed by a PPI, clarithromycin, and tinidazole for an additional 5 days. Whether metronidazole or other imidazoles can be used in place of tinidazole has not yet been established. This regimen has achieved eradication rates superior to clarithromycin-based triple therapy and was well tolerated in children, adults, and elderly patients infected with $H$. pylori (138-141). Further, sequential therapy may be superior to clarithromycin triple therapy in patients with clarithromycin-resistant H. pylori strains. A post hoc analysis from a large multicenter trial evaluated the efficacy of sequential therapy versus clarithromycin triple therapy $(82 \%$ [18/22] vs 44\% [7/16], $P<0.0155)$ in a subset of patients with clarithromycin-resistant $H$. pylori (142). In the available studies, the reported compliance with therapy has exceeded $90 \%$ and side effects have been no greater than those experienced with clarithromycin triple therapy. Several important questions remain to be answered regarding this promising regimen before it can be accepted as a standard first-line therapy in the United States. Perhaps most importantly, validation of this promising new therapy in North America is necessary. In addition, it is not clear that there is any incremental benefit to providing antibiotic therapy sequentially rather than as a concurrent quadruple regimen.

\section{Predictors of H. pylori Treatment Outcome}

The most important predictors of treatment failure following anti-H. pylori therapy include poor compliance and antibiotic resistance. There is limited evidence to suggest that smoking, alcohol consumption, and diet may also adversely affect the likelihood of successful eradication (143).

It is critical for clinicians to stress the importance of taking the medications as prescribed to minimize the likelihood of treatment failure and development of antibiotic resistance. Patients should also be informed of the most commonly reported treatment-related side effects. While mild side effects are very common with any of the recommended $H$. pylori treatment regimens, significant side effects are reported in only 5-20\% (144). The most commonly reported side effects with the PPIs include headache and diarrhea, occurring in up to $10 \%$ of patients. To optimize their effects on gastric acid secretion, PPIs should be taken 30-60 minutes before eating. The most frequent side effects reported with clarithromycin include GI upset, diarrhea, and altered taste. Common side ef- fects associated with amoxicillin include GI upset, headache, and diarrhea. Side effects of metronidazole tend to be dose related and include a metallic taste in the mouth, dyspepsia, and a disulfiram-like reaction with alcohol consumption. Common side effects of tetracycline include GI upset and photosensitivity. This antibiotic should not be used in children under 8 yr of age because of possible tooth discoloration. Finally, bismuth compounds have been associated with darkening of the tongue and stool, nausea, and GI upset (145). Informed patients are less likely to be alarmed when side effects that they are aware of occur and, consequently, less likely to needlessly stop their treatment.

Antibiotic resistance must also be carefully considered when choosing amongst the various anti-H. pylori treatment regimens. A recent multicenter U.S. study which collected data from 1993 to 1999 reported antibiotic resistance rates amongst $H$. pylori strains of $37 \%$ for metronidazole, $10 \%$ for clarithromycin, $3.9 \%$ for both antibiotics, and $1.4 \%$ for amoxicillin (146). Subsequent data collected from 1998 to 2002 yielded resistance rates of $25 \%$ for metronidazole, $13 \%$ for clarithromycin, $5 \%$ for at least 2 antibiotics, and $0.9 \%$ for amoxicillin (147). Though these data sets are difficult to directly compare, it appears that metronidazole and amoxicillin resistance have remained relatively stable while clarithromycin resistance has increased. The increasing background rate of clarithromycin resistance provides at least a partial explanation for the decreasing efficacy of traditional clarithromycin-containing regimens. It is quite clear that clarithromycin resistance, which has been attributed to several different point mutations in the peptidyltransferase region encoded in domain V of the $23 \mathrm{~S}$ rRNA gene (142), is associated with a high rate of treatment failure when clarithromycincontaining regimens are employed (148-150). On the other hand, metronidazole resistance appears to be more relative. To some extent, metronidazole resistance can be overcome by the use of higher doses of metronidazole and/or the addition of a PPI to bismuth, tetracycline, and metronidazole (143). An important study found that previous treatment with either a macrolide or metronidazole for any reason significantly increased the likelihood of $H$. pylori resistance to these agents (151). As such, clinicians should routinely ask about previous macrolide or metronidazole use when deciding upon an H. pylori treatment regimen. Further, it seems reasonable to consider bismuth quadruple therapy with a PPI or sequential therapy in individuals who have previously been treated with clarithromycin or metronidazole.

Recent data suggest that bacterial and host factors also influence treatment outcomes. A systematic review and metaanalysis including 14 studies (1,529 patients) found that CagA-negative strains of $H$. pylori were associated with an increased risk of treatment failure compared with CagApositive strains (risk ratio of treatment failure 2.0, 95\% CI 1.6-2.4) (152). Another meta-analysis found that CYP2C19 polymorphisms, which influence the clearance of PPIs and thus their effect on gastric acid secretion, could influence treatment outcomes when regimens containing a PPI are used 
(153). These observations are of greatest importance to far eastern countries where the extensive metobolizer status is more common. Further, the inability of the clinician to readily determine CagA status of $H$. pylori or the cytochrome P450 status of their patients makes these observations unlikely to change clinical practice in the immediate future.

\section{Salvage Therapy for Persistent H. pylori Infection}

- In patients with persistent $\mathrm{H}$. pylori infection, every effort should be made to avoid antibiotics that have been previously taken by the patient.

- Bismuth-based quadruple therapy for 7-14 days is an accepted salvage therapy.

- Levofloxacin-based triple therapy for 10 days is another option in patients with persistent infection, which requires validation in the United States.

When faced with a patient who has failed an initial course of therapy for $H$. pylori, the clinician should avoid using antibiotics employed in previous treatment regimens. Because of the expense and lack of availability, culture and antibiotic sensitivity testing are typically not performed unless a patient has failed at least 2 courses of therapy. Even in this circumstance, the usefulness of such testing is arguable as there is no evidence to suggest that choosing a salvage regimen based upon an understanding of the patient's previous antibiotic exposure is any less successful than choosing an antibiotic regimen based upon the results of antimicrobial sensitivity testing. Recommendations regarding salvage therapy regimens are provided in Table 5.

If a patient with persistent infection has not been previously treated with clarithromycin, triple therapy with a PPI, clarithromycin, and amoxicillin or metronidazole can be considered.

Unfortunately, most patients are initially treated with a clarithromycin-containing regimen. In such circumstances, the most frequently used "rescue" or "salvage" therapy is bismuth quadruple therapy consisting of a PPI, tetracycline, metronidazole, and bismuth (104). This salvage regimen is widely available, inexpensive, and relatively effective. A pooled analysis of 16 studies and 24 abstracts demonstrated an average eradication rate of $76 \%$ (range $60-100 \%$ ) for quadruple therapy when used as second-line therapy (154). Unfortunately, the data on quadruple therapy are difficult to interpret as antibiotic dosing, frequency of administration, and duration of therapy vary between studies. Further, the available studies often do not clearly report how many times or with which antibiotics a patient has previously been treated. As has already been discussed, disadvantages of bismuthbased quadruple therapy include the large daily pill count (potentially exceeding 18 pills), dosing frequency (typically four times daily), and frequent side effects. In the hopes of addressing some of these issues, a simplified twice-daily regimen was recently evaluated and reported to yield an eradication rate of over $90 \%$ in patients who had received at least 2 previous courses of antibiotic therapy (155). Though most international studies have utilized this regimen for 7 days (104), a 10-14 day course is still most commonly employed in the United States.

A number of recent studies have evaluated alternatives to bismuth-based quadruple salvage therapy. Rifabutin, an antibiotic used in the treatment of tuberculosis, has been utilized as an alternative to clarithromycin in several small studies with eradication rates ranging from $38 \%$ to $91 \%$ (156159). In a recent study from Australia, 137 patients who had failed therapy with omeprazole, clarithromycin, and amoxicillin were treated with a 12-day course of rifabutin $150 \mathrm{mg}$, pantoprazole $80 \mathrm{mg}$, and amoxicillin $1 \mathrm{~g}$ or $1.5 \mathrm{~g}$ daily. The overall eradication rate was $91 \%$ and the presence of clarithromycin or metronidazole resistance did not influence the likelihood of treatment success (160). The most common side effects with rifabutin include rash and gastrointestinal complaints including nausea, vomiting, dyspepsia, and diarrhea. Rifabutin has been associated with rare but potentially serious myelotoxicity and ocular toxicity (161, 162).

Patients should be warned about the possibility of red discoloration of urine while taking rifabutin.

Furazolidone, an antibiotic commonly used to treat giardia, cholera, and bacterial enteritis has been evaluated as an alternative to clarithromycin, metronidazole, or amoxicillin for persistent $H$. pylori infection. Available studies utilizing furazolidone have yielded widely variable eradication rates, ranging from $52 \%$ to $90 \%$ (163-166). Unfortunately, furazolidone is not currently marketed in the United States. Side effects including nausea, vomiting, headache, and malaise occur in up to a third of patients. Less frequent side effects include hypersensitivity, hypotension, a disulfiram-like reaction to alcohol, and mild, reversible hemolytic anemia (163167).

Table 5. Salvage Therapies for Persistent H. pylori Infection (164)

\begin{tabular}{lccc}
\hline Regimen & Duration & Eradication Rates & Comments \\
\hline $\begin{array}{l}\text { Bismuth quadruple therapy } \\
\text { PPI q.d. tetracycline, Pepto Bismol, metronidazole q.i.d. }\end{array}$ & 7 & $68 \%$ (95\% CI 62-74\%) & $\begin{array}{c}\text { Accessible, cheap but high pill count and } \\
\text { frequent mild side effects }\end{array}$ \\
$\begin{array}{l}\text { Levofloxacin triple therapy } \\
\text { PPI, amoxicillin 1 g b.i.d., levofloxacin 500 mg q.d. }\end{array}$ & 10 & $87 \%$ (95\% CI 82-92\%) & Requires validation in North America \\
\hline
\end{tabular}

For recommendations regarding rifabutin and furazolidone, please refer to the text.

PPI = proton pump inhibitor; q.d. = daily; q.i.d. = four times daily; b.i.d. = twice daily 
Levofloxacin is a fluoroquinolone antibiotic with in vitro activity against $H$. pylori. Levofloxacin-based triple therapy (PPI, levofloxacin, and amoxicillin) has recently been studied as second- and third-line therapy in patients with persistent $H$. pylori infection. In general, the available clinical trials have involved relatively small numbers of patients and demonstrated variable eradication rates, ranging from $63 \%$ to $94 \%$ (168-170). A recent meta-analysis including four randomized controlled trials found that a 10-day regimen of levofloxacin-based triple therapy yielded superior eradication (RR 1.41, 95\% CI 1.25-1.59) and was associated with fewer side effects (RR $0.51,95 \%$ CI $0.34-0.75$ ) than a 7-day course of bismuth-based quadruple therapy. Summary eradication rates for levofloxacin-based triple therapy and bismuth-based quadruple therapy were $87 \%$ (95\% CI $82-92 \%)$ and $68 \%$ (95\% CI 62-74\%), respectively (168). A recent study from Italy found that using rabeprazole, levofloxacin, and tinidazole in place of amoxicillin yielded an ITT eradication rate of $84 \%$ (171). Unfortunately, none of the studies that have evaluated levofloxacin-based triple therapy, have been conducted in the United States. As such, these encouraging results require validation in the United States. The background rate of $H$. pylori resistance to levofloxacin in the United States remains largely unknown. However, preliminary data from Canada, Italy, Belgium, and Japan suggest that such resistance is found in up to $16.8 \%$ of H. pylori strains (172-175). Whether levofloxacin resistance is absolute as is the case with clarithromycin or more relative as with metronidazole remains to be determined as well. While awaiting data on antimicrobial resistance and efficacy from the United States, given the shortage of effective, validated salvage regimens, it seems reasonable to consider levofloxacin-based triple therapy in circumstances where bismuth or clarithromycin-based therapies are not an option.

\section{STUDY HIGHLIGHTS}

\section{What Is Current Knowledge}

- H. pylori is a common worldwide infection.

- Established indications for H. pylori cure include peptic ulcer, gastric mucosa associated lymphoid tissue (MALT), and uninvestigated dyspepsia.

- Nonendoscopic and endoscopic tests are available to identify $H$. pylori.

- Proton pump inhibitor (PPI), clarithromycin, and amoxicillin or metronidazole or a PPI, bismuth, tetracycline, and metronidazole for 10-14 days are accepted first line treatments for $H$. pylori.

\section{What Is New Here}

- A subset of patients with functional dyspepsia derives benefit from $H$. pylori eradication.

- Emerging evidence suggests an association between H. pylori and unexplained iron deficiency anemia.
- In populations with a low pretest probability of $H$. pylori infection, nonendoscopic tests such as the urea breath test and fecal antigen test offer superior positive predictive value compared with antibody tests.

- Eradication rates with a PPI, clarithromycin, and amoxicillin are decreasing worldwide. Fourteen-day courses of therapy are more effective than seven-days treatment regimens.

- Newer treatments such as sequential therapy require validation in the United States before they can be recommended as a standard first-line therapy.

- A PPI, levofloxacin, and amoxicillin for 10 days appear to be more effective and better tolerated than a PPI, bismuth, tetracycline, and metronidazole in patients with persistent $H$. pylori infection but require validation in North America.

Reprint requests and correspondence: William D. Chey, F.A.C.G., A.G.A.F., F.A.C.P., Associate Professor of Internal Medicine, Director-GI Physiology Laboratory, University of Michigan Medical Center, 3912 Taubman Center, -0362 Ann Arbor, MI 48109.

Received November 3, 2006; accepted January 11, 2007.

\section{REFERENCES}

1. Everhart JE. Recent developments in the epidemiology of Helicobacter pylori. Gastroenterol Clin N Am 2000;29:559-78.

2. Peterson WL, Fendrick AM, Cave DR, et al. Helicobacter pylori-related disease: Guidelines for testing and treatment. Arch Intern Med 2000;160:1285-91.

3. Howden CW, Hunt RH. Guidelines for the management of Helicobacter pylori infection. Am J Gastroenterol 1998;93:2330-8.

4. Paptheodoridis GV, Sougioultzis S, Archimandritis AJ. Effects of Helicobacter pylori and nonsteroidal antiinflammatory drugs on peptic ulcer disease: A systematic review. Clin Gastroenterol Hepatol 2006;4:13042.

5. Leodolter A, Kulig M, Brasch H, et al. A meta-analysis comparing eradication, healing and relapse rates in patients with Helicobacter pylori-associated gastric or duodenal ulcer. Aliment Pharmacol Ther 2001;15:1949-58.

6. Ford AC, Delaney BC, Forman D, et al. Eradication therapy in Helicobacter pylori positive peptic ulcer disease: Systematic review and economic analysis. Am J Gastroenterol 2004;99:1833-55.

7. Sharma VK, Sahai AV, Corder FA, et al. Helicobacter pylori eradication is superior to ulcer healing with or without maintenance therapy to prevent further ulcer haemorrhage. Aliment Pharmacol Ther 2001;15:1939-47.

8. Liu CC, Lee CL, Chan CC, et al. Maintenance treatment is not necessary after Helicobacter pylori eradication and healing of bleeding peptic ulcer. Arch Intern Med 2003;163:2020-4.

9. Gisbert JP, Khorrami S, Carballo F, et al. H. pylori eradication therapy vs. antisecretory non-eradication therapy (with or without long-term maintenance antisecretory therapy) for the prevention of recurrent bleeding from peptic ulcer. Cochrane Database Syst Rev 2004;(2):CD004062. 
10. Farinha P, Gascoyne RD. Helicobacter pylori and MALT lymphoma. Gastroenterology 2005;128:1579-605.

11. Montalban C, Norman F. Treatment of gastric mucosaassociated lymphoid tissue lymphoma: Helicobacter pylori eradication and beyond. Expert Rev Anticancer Ther 2006;6:361-71.

12. Wundisch T, Thiede C, Morgner A, et al. Long-term follow-up gastric MALT lymphoma after Helicobacter pylori eradication. J Clin Oncol 2001;23:8018-24.

13. Nakamura S, Matsumoto T, Suekane H, et al. Long-term clinical outcome of Helicobacter pylori eradication for gastric mucosa-associated lymphoid tissue lymphoma with a reference to second-line treatment. Cancer 2005;104:53240 .

14. Chen LT, Lin JT, Tai JJ, et al. Long-term results of antiHelicobacter pylori therapy in early-stage gastric highgrade transformed MALT lymphoma. J Natl Cancer Inst 2005;97:1345-53.

15. Talley NJ, Vakil N. Practice Parameters Committee of the American College of Gastroenterology. Guidelines for the management of dyspepsia. Am J Gastroenterol 2005; 100:2324-37.

16. McColl K, Murray L, El-Omar E, et al. Symptomatic benefit from eradicating Helicobacter pylori infection in patients with nonulcer dyspepsia. N Engl J Med 1998;339:1869-74.

17. McNamara D, Buckley M, Gilvarry J, et al. Does $\mathrm{He}$ licobacter pylori eradication affect symptoms in nonulcer dyspepsia: A 5-year follow-up study. Helicobacter 2002; 7:317-21.

18. Malfertheiner P, Mössner J, Fischbach W, et al. Helicobacter pylori eradication is beneficial in the treatment of functional dyspepsia. Aliment Pharmacol Ther 2003;18:61525.

19. Kamada T, Haruma K, Hata J, et al. The long-term effect of Helicobacter pylori eradication therapy on symptoms in dyspeptic patients with fundi atrophic gastritis. Aliment Pharmacol Ther 2003;18:245-52.

20. Blum AL, Talley NJ, O’Moráin C, et al. Lack of effect of treating Helicobacter pylori infection in patients with nonulcer dyspepsia. N Engl J Med 1998;339:1875-81.

21. Koskenpato J, Färkkilä M, Sipponen P. Helicobacter pylori eradication and standardized 3-month omeprazole therapy in functional dyspepsia. Am J Gastroenterol 2001;96:2866-72.

22. Froehlich F, Gonvers JJ, Wietlisbach V, et al. Helicobacter pylori eradication treatment does not benefit patients with nonulcer dyspepsia. Am J Gastroenterol 2001;96:2329-36.

23. Veldhuyzen van Zanten S, Fedorak RN, Lambert J, et al. Absence of symptomatic benefit of lansoprazole, clarithromycin, and amoxicillin triple therapy in eradication of Helicobacter pylori positive, functional (nonulcer) dyspepsia. Am J Gastroenterol 2003;98:1963-9.

24. Talley NJ, Vakil N, Ballard ED 2nd, et al. Absence of benefit of eradicating Helicobacter pylori in patients with nonulcer dyspepsia. N Engl J Med 1999;341:1106-11.

25. Moayyedi P, Deeks J, Talley NJ, et al. An update of the Cochrane systematic review of Helicobacter pylori eradication therapy in nonulcer dyspepsia: Resolving the discrepancy between systematic reviews. Am J Gastroenterol 2003;98:2621-6.

26. Moayyedi P, Soo S, Deeks J, et al. Eradication of Helicobacter pylori for non-ulcer dyspepsia. Cochrane Database Syst Rev 2003;(1):CD002096.

27. Gilvarry J, Buckley MJ, Beattie S, et al. Eradication of $H$. pylori affects symptoms in non-ulcer dyspepsia. Scand J Gastroenterol 1997;32:535-40.
28. Hsu PI, Lai KH, Tseng HH, et al. Eradication of Helicobacter pylori prevents ulcer development in patients with ulcer-like functional dyspepsia. Aliment Pharmacol Ther 2001;15:195-201.

29. Hsu PI, Lai KH, Lo GH, et al. Risk factors for ulcer development in patients with non-ulcer dyspepsia: A prospective two year follow up study of 209 patients. Gut 2002;51:1520.

30. Pandolfino JE, Howden CW, Kahrilas PJ. H. pylori and GERD: Is less more? Am J Gastroenterol 2004;99:12225 .

31. Vakil N, Talley NJ, Stolte M, et al. Patterns of gastritis and the effect of eradicating Helicobacter pylori on gastrooesophageal reflux disease in Western patients with nonulcer dyspepsia. Aliment Pharmacol Ther 2006;24:5563.

32. Cremonini F, Di Caro S, Delgado-Aros S, et al. Metaanalysis: The relationship between Helicobacter pylori infection and gastro-oesophageal reflux disease. Aliment Pharmacol Ther 2003;18:279-89.

33. Raghunath A, Hungin AP, Wooff D, et al. Prevalence of Helicobacter pylori in patients with gastro-oesophageal reflux disease: Systematic review. BMJ 2003;326:737-43.

34. Raghunath AS, Hungin APS, Wooff D, et al. Systematic review: The effect of Helicobacter pylori and its eradication on gastro-oesophageal reflux disease in patients with duodenal ulcers or reflux oesophagitis. Aliment Pharmacol Ther 2004;20:733-44.

35. Laine L, Sugg J. Effect of Helicobacter pylori eradication on development of erosive esophagitis and gastroesophageal reflux disease symptoms: A post hoc analysis of eight double blind prospective studies. Am J Gastroenterol 2002;97:2992-7.

36. Vakil N, Traxler BM, Levine D. Symptom response and healing of erosive esophagitis with proton-pump inhibitors in patients with Helicobacter pylori infection. Am J Gastroenterol 2004;99:1437-41.

37. De Wit NJ, de Boert WA, Geldof H, et al. Treatment of gastro-oesophageal reflux disease with rabeprazole in primary and secondary care: Does Helicobacter pylori infection affect proton pump inhibitor effectiveness? Aliment Pharmacol Ther 2004;20:451-8.

38. Fallone CA, Barkun AN, Mayrand S, et al. There is no difference in the disease severity of gastro-oesophageal reflux disease between patients infected and not infected with Helicobacter pylori. Aliment Pharmacol Ther 2004; 20:761-8.

39. Chan FKL. NSAID-induced peptic ulcers and Helicobacter pylori infection. Implications for patient management. Drug Saf 2005;28:287-300.

40. Sung JJY. Should we eradicate Helicobacter pylori in nonsteroidal anti-inflammatory drug users? Aliment Pharmacol Ther 2004;20(Suppl 2):65-70.

41. Huang JQ, Sridhar S, Hunt RH. Role of Helicobacter pylori infection and non-steroidal anti-inflammatory drugs in peptic-ulcer disease: A meta-analysis. Lancet 2002;359:14-22.

42. Vergara M, Catalán M, Gisbert JP, et al. Meta-analysis: Role of Helicobacter pylori eradication in the prevention of peptic ulcer in NSAID users. Aliment Pharmacol Ther 2005;21:1411-8.

43. Schaeverbeke T, Broutet N, Zerbib F, et al. Should we eradicate Helicobacter pylori before prescribing an NSAID? Results of a placebo-controlled study. Am J Gastroenterol 2005; 100:2637-43.

44. Papatheodoridis GV, Archimandritis AJ. Role of Helicobacter pylori eradication in aspirin or non-steroidal 
anti-inflammatory drug users. World J Gastroenterol 2005;11:3811-6.

45. Eswaran S, Scheiman J, Howden CW, et al. Primary care physician perceptions of non-steroidal anti-inflammatory drug and aspirin-associated toxicity: Results of a national survey. Aliment Pharmacol Ther 2006;23:655-68.

46. Chan FK, Chung SC, Suen BY, et al. Preventing recurrent upper gastrointestinal bleeding in patients with Helicobacter pylori infection who are taking low-dose aspirin or naproxen. N Engl J Med 2001;344:967-73.

47. DuBois S, Kearney, D. Iron-deficiency anemia and Helicobacter pylori infection: A review of evidence. Am J Gastroenterol 2005;100:453-9.

48. Baggett HC, Parkinson AJ, Muth PT, et al. Endemic iron deficiency associated with Helicobacter pylori infection among school-aged children in Alaska. Pediatrics 2006;117:e396-404.

49. Cardenas VM, Mulla ZD, Ortiz M, et al. Iron deficiency and Helicobacter pylori infection in the United States. Am J Epidemiol 2006;163:127-34.

50. Annibale B, Marignani M, Monarca B, et al. Reversal of iron deficiency anemia after Helicobacter pylori eradication in patients with asymptomatic gastritis. Ann Inten Med 1999;131:668-72.

51. Choe YH, Soon KK, Son BK, et al. Randomized placebocontrolled trial of Helicobacter pylori eradication for irondeficiency anemia in preadolescent children and adolescents. Helicobacter 1999;4:135-9.

52. Hacihanefioglu A, Edebali F, Celebi A, et al. Improvement of complete blood count in patients with iron deficiency anemia and Helicobacter pylori infection after the eradication of Helicobacter pylori. Hepatogastroenterology 2004;51:313-5.

53. Gessner BD, Baggett HC, Muth PT, et al. A controlled, household-randomized, open-label trial of the effect that treatment of Helicobacter pylori infection has on iron-deficiency in children in rural Alaska. J Infect Dis 2006;193:537-46.

54. Malfertheiner P, Sipponen P, Naumann M, et al. Helicobacter pylori eradication has the potential to prevent gastric cancer: A state-of-the-art critique. Am J Gastroenterol 2005;100:2100-15.

55. Leung WK, Lin SR, Ching JY, et al. Factors predicting progression of gastric intestinal metaplasia: Results of a randomised trial on Helicobacter pylori eradication. Gut 2004;53:1244-9.

56. Ley C, Mohar A, Guarner J, et al. Helicobacter pylori eradication and gastric preneoplastic conditions: A randomized, double-blind, placebo-controlled trial. Cancer Epidemiol Biomarkers Prev 2004;13:4-10.

57. Mera R, Fontham ETH, Bravo LE, et al. Long term follow up of patients treated for Helicobacter pylori infection. Gut 2005;54:1536-40.

58. Wong BCY, Lam SK, Wong WM, et al. Helicobacter pylori eradication to prevent gastric cancer in a high-risk region of China. JAMA 2004;29:187-94.

59. Midolo P, Marshall BJ. Accurate diagnosis of Helicobacter pylori. Urease tests. Gastroenterol Clin N Am 2000;29:871-8.

60. Perna F, Ricci C, Gatta L, et al. Diagnostic accuracy of a new rapid urease test (Pronto Dry), before and after treatment of Helicobacter pylori infection. Minerva Gastroenterol Dietol 2005;51:247-54.

61. Laine L, Lewin D, Naritoku W, et al. Prospective comparison of commercially available rapid urease tests for the diagnosis of Helicobacter pylori. Gastrointest Endosc 1996;44:523-6.
62. Lee JM, Breslin NP, Fallon C, et al. Rapid urease tests lack sensitivity in Helicobacter pylori diagnosis when peptic ulcer disease presents with bleeding. Am J Gastroenterol 2000;95:1166-70.

63. Tu TC, Lee CL, Wu $\mathrm{CH}$ et al. Comparison of invasive and noninvasive tests for detecting Helicobacter pylori infection in bleeding peptic ulcers. Gastrointest Endosc 1999;49:302-6.

64. Grino P, Pascual S, Such J, et al. Comparison of stool immunoassay with standard methods for detection of Helicobacter pylori infection in patients with uppergastrointestinal bleeding of peptic origin. Eur J Gastroenterol Hepatol 2003;15:525-9.

65. Laine LA, Nathwani RA, Naritoku W. The effect of GI bleeding on Helicobacter pylori diagnostic testing: A prospective study at the time of bleeding and 1 month later. Gastrointest Endosc 2005;62:853-9.

66. Gisbert JP, Abraira V. Accuracy of Helicobacter pylori diagnostic tests in patients with bleeding peptic ulcer: A systematic review and meta-analysis. Am J Gastroenterol 2006;101:848-63.

67. Woo JS, el-Zimaity HM, Genta RM, et al. The best gastric site for obtaining a positive rapid urease test. Helicobacter 1996;1:256-9.

68. Chey WD, Woods M, Scheiman JM, et al. Lansoprazole and ranitidine affect the accuracy of the $14 \mathrm{C}$-urea breath test by a $\mathrm{pH}$-dependent mechanism. Am J Gastroenterol 1997;92:446-50.

69. Laine L, Estrada R, Trujillo M, et al. Effect of proton-pump inhibitor therapy on diagnostic testing for Helicobacter pylori. Ann Intern Med 1998;129:547-50.

70. el-Zimaity HM. Accurate diagnosis of Helicobacter pylori with biopsy. Gastroenterol Clin N Am 2000;29:863-9.

71. Dixon MF, Genta RM, Yardley JH, et al. Classification and grading of gastritis. The updated Sydney system. International workshop on the histopathology of gastritis, Houston 1994. Am J Surg Pathol 1996;20:1161-81.

72. Cutler AF, Havstad S, Chen KM, et al. Accuracy of invasive and non-invasive tests to diagnose Helicobacter pylori infection. Gastroenterology 1995;109:136-41.

73. van IJzendoorn MC, Laheij RJ, de Boer WA, et al. The importance of corpus biopsies in the determination of $\mathrm{He}$ licobacter pylori infection. Neth J Med 2005;63:141-5.

74. Perez-Perez GI. Accurate diagnosis of Helicobacter pylori. Culture, including transport. Gastroenterol Clin N Am 2000;29:879-84.

75. Makristathis A, Hirschl AM, Lehourst P, et al. Diagnosis of Helicobacter pylori Infection. Helicobacter 2004;9:714.

76. Lehours P, Ruskone-Fourmestraux A, Lavergne A, et al. Which test to use to detect Helicobacter pylori infection in patients with low-grade gastric mucosa-associated lymphoid tissue lymphoma? Am J Gastroenterol 2003;98:2915 .

77. Zsikla V, Hailemariam S, Baumann M, et al. Increased rate of Helicobacter pylori infection detected by PCR in biopsies with chronic gastritis. Am J Surg Pathol 2006;30:2428.

78. Lawson AJ, Elviss NC, Owen RJ. Real-time PCR detection and frequency of $16 \mathrm{~S}$ rDNA mutations associated with resistance and reduced susceptibility to tetracycline in Helicobacter pylori from England and Wales. Antimicrob Chemother 2005;56:282-6.

79. Rimbara E, Noguchi N, Yamaguchi T, et al. Development of a highly sensitive method for detection of clarithromycin-resistant Helicobacter pylori from human feces. Current Microbiol 2005;51:1-5. 
80. De Francesco V, Margiotta M, Zullo M, et al. Primary clarithromycin resistance in Italy assessed on Helicobacter pylori DNA sequences by TaqMan real-time polymerase chain reaction. Aliment Pharmacol Ther 2006;23:429-35.

81. Ho GY, Windsor HM. Accurate diagnosis of Helicobacter pylori. Polymerase chain reaction tests. Gastroenterol Clin N Am 2000;29:903-15.

82. Ho B, Marshall BJ. Accurate diagnosis of Helicobacter pylori. Serologic testing. Gastroenterol Clin N Am 2000;29:853-62.

83. Loy CT, Irwig LM, Katelaris PH, et al. Do commercial serological kits for Helicobacter pylori infection differ in accuracy? A meta-analysis. Am J Gastroenterol 1996;91:1138-44.

84. Chey WD, Murthy U, Shaw S, et al. A comparison of three fingerstick, whole blood antibody tests for Helicobacter pylori infection: A United States, multicenter trial. Am J Gastroenterol 1999;94:1512-6.

85. Nurgalieva ZZ, Graham DY. Pearls and pitfalls of assessing Helicobacter pylori status. Dig Liver Dis 2003;35:375-7.

86. Hoang TT, Wheeldon TU, Bengtsson C, et al. Enzymeliked immunosorbent assay for Helicobacter pylori needs adjustment for the population investigated. J Clin Microbiol 2004;42:627-30.

87. Gisbert JP, Pajares JM. Review article: ${ }^{13} \mathrm{C}$-urea breath test in the diagnosis of Helicobacter pylori infection - a critical review. Aliment Pharmacol Ther 2004;20:1001-17.

88. Chey WD. Accurate diagnosis of Helicobacter pylori. ${ }^{14} \mathrm{C}$ urea breath test. Gastroenterol Clin N Am 2000;29:895902.

89. Steen T, Berstad K, Meling T, et al. Reproducibility of the $14 \mathrm{C}$-urea breath test repeated after 1 week. Am J Gastroenterol 1995;90:2103-5.

90. Leodolter A, Domíngues-Muñoz JE, von Arnim U, et al Validity of a modified ${ }^{13} \mathrm{C}$-urea breath test for pre- and posttreatment diagnosis of Helicobacter pylori infection in the routine clinical setting. Am J Gastroenterol 1999;94:2100 4.

91. Chey WD, Metz DC, Shaw S, et al. Appropriate timing of the $14 \mathrm{C}$-urea breath test to establish eradication of Helicobacter pylori infection. Am J Gastroenterol 2000;95:1171-4.

92. Perri F, Giampiero M, Neri M, et al. Helicobacter pylori antigen stool test and $13 \mathrm{C}$-urea breath test in patients after eradication treatments. Am J Gastroenterol 2002;97:275662.

93. Gatta L, Ricci C, Tampieri A, et al. Accuracy of breath tests using low doses of $13 \mathrm{C}$-urea to diagnose Helicobacter pylori infection: A randomised controlled trial. Gut 2006;55:457-62.

94. Chey WD, Murthy U, Toskes P, et al. The 13 C-urea blood test accurately detects active Helicobacter pylori infection: A United States, multicenter trial. Am J Gastroenterol 1999;94:1522-4.

95. Ahmed F, Chey WD, Murthy U. Evaluation of the EzHBT Helicobacter blood test to establish Helicobacter pylori eradication. Aliment Pharmacol Ther 2005;22:87580 .

96. Graham DY, Opekun AR, Hammoud F, et al. Studies regarding the mechanism of false negative urea breath tests with proton pump inhibitors. Am J Gastroenterol 2003;98:1005-9.

97. Cutler AF, Elnaggar M, Brooks E, et al. Effect of standard and high dose ranitidine on $13 \mathrm{C}$-urea breath test results. Am J Gastroenterol 1998;93:1297-9.

98. Savarino V, Tracci D, Dulbecco P, et al. Negative effect of ranitidine on the results of urea breath test for the diagnosis of Helicobacter pylori. Am J Gastroenterol 2001;96:34852.

99. Graham DY, Opekun AR, Jogi M, et al. False negative urea breath tests with $\mathrm{H} 2$-receptor antagonists: Interactions between Helicobacter pylori density and $\mathrm{pH}$. Helicobacter 2004;9:17-27.

100. Gatta L, Vakil N, Ricci C, et al. Effect of proton pump inhibitors and antacid therapy on $13 \mathrm{C}$ urea breath tests and stool test for Helicobacter pylori infection. Am J Gastroenterol 2004;99:823-9.

101. Gatta L, Ricci C, Tampieri A, et al. Accuracy of breath tests using low doses of ${ }^{13} \mathrm{C}$-urea to diagnose Helicobacter pylori infection: A randomised controlled trial. Gut 2006;55:457-62.

102. Gisbert JP, Pajares JM. Stool antigen test for the diagnosis of Helicobacter pylori infection: A systematic review. Helicobacter 2004;9:347-68.

103. Gisbert JP, de la Morena F, Abraira V. Accuracy of monoclonal stool antigen test for the diagnosis of $H$. pylori infection: A systematic review and meta-analysis. Am J Gastroenterol 2006;101:1921-30.

104. Malfertheiner P, Megraud F, O’Morain C, et al. Current concepts in the management of Helicobacter pylori infection-the Maastricht 2-2000 Consensus Report. Aliment Pharmacol Ther 2002;16:167-80.

105. Viara D, Vakil N, Menegatti M, et al. The stool antigen test for detection of Helicobacter pylori after eradication therapy. Ann Intern Med 2002;136:280-7.

106. Odaka T, Yamaguchi T, Koyama H, et al. Evaluation of the Helicobacter pylori stool antigen test for monitoring eradication therapy. Am J Gastroenterol 2002;97:594-9.

107. Vakil N, Rhew D, Soll A, et al. The cost-effectiveness of diagnostic testing strategies for Helicobacter pylori. Am J Gastroenterol 2000;95:1691-8.

108. Bravo LE, Realpe JL, Campo C, et al. Effects of acid suppression and bismuth medications on the performance of diagnostic tests for Helicobacter pylori infection. Am J Gastroenterol 1999;94:2380-3.

109. Manes G, Balzano A, Iaquinto G, et al. Accuracy of the stool antigen test in the diagnosis of Helicobacter pylori infection before treatment and in patients on omeprazole therapy. Aliment Pharmacol Ther 2001;15:73-9.

110. Grino P, Pascual S, Such J, et al. Comparison of stool immunoassay with standard methods for detection of Helicobacter pylori infection in patients with uppergastrointestinal bleeding of peptic origin. Eur J Gastroenterol Hepatol 2003;15:525-9.

111. Peitz U, Leodolter A, Kahl S, et al. Antigen stool test for assessment of Helicobacter pylori infection in patients with upper gastrointestinal bleeding. Aliment Pharmacol Ther 2003; 17:1075-84

112. van Leerdam ME, Van Der Ende A, ten Kate FJW, et al. Lack of accuracy of the noninvasive Helicobacter pylori stool antigen test in patients with gastroduodenal ulcer bleeding. Am J Gastroenterol 2003;98:798-801.

113. Lin HJ, Lo WC, Perng CL, et al. Helicobacter pylori stool antigen test in patients with bleeding peptic ulcers. Helicobacter 2004;9:663-8.

114. Grino P, Pascual S, Such J, et al. Comparison of diagnostic methods for Helicobacter pylori infection in patients with upper gastrointestinal bleeding. Scand J Gastroenterol 2001;36:1254-8.

115. Schilling D, Demel A, Adamek HE, et al. A negative rapid urease test is unreliable for exclusion of Helicobacter pylori infection during acute phase of ulcer bleeding. A prospective case control study. Dig Liver Dis 2003;35:21721. 
116. Güell M, Artigau E, Esteve V, et al. Usefulness of a delayed test for the diagnosis of Helicobacter pylori infection in bleeding peptic ulcer. Aliment Pharmacol Ther 2006;23:53-9.

117. Talley NJ. AGA Medical Position Statement: Evaluation of dyspepsia. Gastroenterology 2005;129:1753-5.

118. Chey WD, Fendrick AM. Noninvasive Helicobacter pylori testing for the "test-and-treat" strategy: A decision analysis to assess the effect of past infection on test choice. Arch Intern Med 2001;161:2129-32.

119. Laine L, Sugg J, Suchower L, et al. Endoscopic biopsy requirements for post-treatment diagnosis of Helicobacter pylori. Gastrointest Endosc 2000;51:664-9.

120. Qasim A, Sebastian S, Thornton O, et al. Riabutin- and furazolidone-based Helicobacter pylori eradication therapies after failure of standard first- and second-line eradication attempts in dyspepsia patients. Aliment Pharmacol Ther 2005;21:91-6.

121. Katelaris PH, Forbes GM, Talley NJ, et al. A randomized comparison of quadruple and triple therapies for Helicobacter pylori eradication: The QUADRATE study. Gastroenterology 2002;123:1763-9.

122. Gené E, Calvet X, Azagra R, et al. Triple vs. quadruple therapy for treating Helicobacter pylori infection: A metaanalysis. Aliment Pharmacol Ther 2003;17:1137-43.

123. Vakil N, Lanza F, Schwatrz H, et al. Seven-day therapy for Helicobacter pylori in the United States. Aliment Pharmacol Ther 2004;20:99-107.

124. Cardenas VM, Graham DY, el-Zimaity HM, et al. Rabeprazole containing triple therapy to eradicate Helicobacter pylori infection on the Texas-Mexican border. Aliment Pharmacol Ther 2006;23:295-301.

125. Bochenek WL, Peters S, Fraga PD, et al. Eradication of Helicobacter pylori by 7-day triple-therapy regimens combining pantoprazole with clarithromycin, metronidazole, or amoxicillin in patients with peptic ulcer disease: Results of two double-blind, randomized studies. Helicobacter 2003;8:626-42.

126. Calvet X, Garcia N, Lopez T, et al. A meta-analysis of short versus long therapy with a proton pump inhibitor, clarithromycin and either metronidazole or amoxycillin for treating Helicobacter pylori infection. Aliment Pharmacol Ther 2000;14:603-9.

127. Paoluzi P, Iacopini F, Crispino P, et al. 2-week triple therapy for Helicobacter pylori infection is better than 1-week in clinical practice: A large prospective single-center randomized study. Helicobacter 2006;11:562-8.

128. Ulmer HJ, Beckerling A, Gatz G. Recent use of proton pump inhibitor-based triple therapies for the eradication of H pylori: A broad data review. Helicobacter 2003;8:95104.

129. Vergara M, Vallve M, Gisbert JP, et al. Meta-analysis: Comparative efficacy of different proton-pump inhibitors in triple therapy for Helicobacter pylori eradication. Aliment Pharmacol Ther 2003;18:647-54.

130. Vallve M, Vergara M, Gisbert JP, et al. Single vs. double dose of a proton pump inhibitor in triple therapy for Helicobacter pylori eradication: A meta-analysis. Aliment Pharmacol Ther 2002;16:1149-56.

131. Janssen MJ, Laheij RJ, de Boer WA, et al. Meta-analysis: The influence of pre-treatment with a proton pump inhibitor on Helicobcacter pylori eradication. Aliment Pharmacol Ther 2005;21:341-5.

132. Graham DY, Hammoud F, el-Zimaity HM, et al. Metaanalysis: Proton pump inhibitor or $\mathrm{H}_{2}$-receptor antagonist for Helicobacter pylori eradication. Aliment Pharmacol Ther 2003;17:1229-36.
133. Laine L. Is it time for quadruple therapy to be first line? Can J Gastroenterol 2003;17(Suppl B):33B-5B.

134. Gene E, Calvet X, Azagra R, et al. Triple vs. quadruple therapy for treating Helicobacter pylori infection: An updated meta-analysis. Aliment Pharmacol Ther 2003;18:543-4.

135. Fischbach LA, van Zanten S, Dickason J. Meta-analysis: The efficacy, adverse events, and adherence related to firstline anti-Helicobacter pylori quadruple therapies. Aliment Pharmacol Ther 2004;20:1071-82.

136. Graham DY, Belson G, Abudayyeh S, et al. Twice daily (mid-day and evening) quadruple therapy for $H$. pylori infection in the United States. Dig Liver Dis 2004;36:384-7.

137. Laine L, Hunt R, el-Zimaity H, et al. Bismuth-based quadruple therapy using a single capsule of bismuth biskalcitrate, metronidazole, and tetracycline given with omeprazole versus omeprazole, amoxicillin, and clarithromycin for eradication of Helicobacter pylori in duodenal ulcer patients: A prospective, randomized, multicenter, North American trial. Am J Gastroenterol 2003;98:562-7.

138. Zullo A, Vaira D, Vakil N, et al. High eradication rates of Helicobacter pylori with a new sequential treatment. Aliment Pharmacol Ther 2003;17:719-26.

139. Francavilla R, Lionetti E, Castellaneta SP, et al. Improved Efficacy of 10-day sequential treatment for Helicobacter pylori eradication in children: A randomized trial. Gastroenterol 2005;129:1414-9.

140. Zullo A, Gatta L, de Francesco V, et al. High rate of Helicobacter pylori eradication with sequential therapy in elderly patients with peptic ulcer: A prospective controlled study. Aliment Pharmacol Ther 2005;21:1419-24.

141. Scaccianoce G, Hassan C, Panarese A, et al. Helicobacter pylori eradication with either 7-day or 10-day triple therapies, and with a 10-day sequential regimen. Can J Gastroenterol 2006;20:113-7.

142. De Francesco V, Margiotta M, Zullo A, et al. Clarithromycin-resistant genotypes and eradication of $\mathrm{He}$ licobacter pylori. Ann Intern Med 2006;144:94-100.

143. Megraud F, Lamouliatte H. Review article: The treatment of refractory Helicobacter pylori infection. Aliment Pharmacol Ther 2003;17:1333-43.

144. Megraud F, Marshall BJ. How to treat Helicobacter pylori. First-line, second-line, and future therapies. Gastroenterol Clin N Am 2000;29:759-73.

145. Saad R, Chey WD. A clinician's guide to the diagnosis and treatment of $H$. pylori. Cleve Clin J Med 2005;72:10926.

146. Meyer JM, Silliman NP, Wang W, et al. Risk factors for Helicobacter pylori resistance in the United States: The surveillance of $H$. pylori antimicrobial resistance partnership (SHARP) study, 1993-1999. Ann Intern Med 2002;136:13-24.

147. Duck WM, Sobel J, Pruckler JM, et al. Antimicrobial resistance incidence and risk factors among Helicobacter pylori-infected persons, United States. Emerg Infect Dis 2004;10:1088-94.

148. Tankovic J, Lamarque D, Lascols C, et al. Impact of Helicobacter pylori resistance to clarithromycin on the efficacy of the omeprazole-amoxicillin-clarithromycin therapy. A1iment Pharmacol Ther. 2001;15;707-13.

149. Ducons JA, Santolaria S, Guirao R, et al. Impact of clarithromycin resistance on the effectiveness of a regimen for Helicobacter pylori: A prospective study of 1-week lansoprazole, amoxycillin and clarithromycin in active peptic ulcer. Aliment Pharmacol Ther 1999;13:775-80.

150. Lee JH, Shin JH, Roe IH, et al. Impact of clarithromycin resistance on eradication of Helicobacter pylori in infected adults. Antimicrob Agents Chemother 2005;49:1600-3. 
151. McMahon BJ, Hennessy TW, Bensler JM, et al. The relationship among previous antimicrobial use, antimicrobial resistance, and treatment outcomes for Helicobacter pylori infections. Ann Intern Med 2003;139:463-9.

152. Suzuki T, Matsuo K, Sawaki A, et al. Systematic review and meta-analysis: Importance of CagA status for successful eradication of Helicobacter pylori infection. Aliment Pharmacol Ther 2006;24:273-80.

153. Padol S, Yuan Y, Thabane M, et al. The effect of CTP2C19 polymorphisms on $H$ pylori eradication rate in dual and triple first-line PPI therapies: A meta-analysis. Am J Gastroenterol 2006;101:1467-75.

154. Hojo M, Miwa H, Nagahara A, et al. Pooled analysis on the efficacy of the second-line treatment regimens for Helicobacter pylori infection. Scand J Gastroenterol 2001;36:690-700.

155. Dore MP, Marras L, Maragkoudakis E, et al. Salvage therapy after two or more prior Helicobacter pylori treatment failures: The super salvage regimen. Helicobacter 2003;8:307-9.

156. Perri F, Festa V, Clemente R, et al. Randomized study of two "rescue" therapies for Helicobacter pylori-infected patients after failure of standard triple therapies. Am J Gastroenterol 2001;96:58-62.

157. Bock H, Koop H, Lehn N, et al. Rifabutin-based triple therapy after failure of Helicobacter pylori eradication treatment: Preliminary experience. J Clin Gastroenterol 2000;31:222-5.

158. Wong WM, Gu Q, Lam SK, et al. Randomised controlled study of rabeprazole, levofloxacin and rifabutin triple therapy versus quadruple therapy as second-line treatment of Helicobacter pylori infection. Aliment Pharmacol Ther 2003;17:553-60.

159. Miehlke S, Hansky K, Schneider-Brachert W, et al. Randomized trial of rifabutin-based triple therapy and highdose dual therapy for rescue treatment of Helicobacter pylori resistant to both metronidazole and clarithromycin. Aliment Pharmacol Ther 2006;24:395-403.

160. Borody TJ, Pang G, Wettstein AR, et al. Efficacy and safety of rifabutin-containing 'rescue-therapy' for resistant Helicobacter pylori infection. Aliment Pharmacol Ther 2006;23:481-8.

161. Apseloff G. Severe neutropenia among healthy volunteers given rifabutin in clinical trials. Clin Pharmacol Ther 2003;74:591-2.

162. Bhagat N, Read RW, Rao NA, et al. Rifabutin-associated hypopyon uveitis in human immunodeficiency virusnegative immunocompetent individuals. Ophthalmology 2001;108:750-2.

163. Graham DY, Osato MS, Hoffman J, et al. Furazolidone combination therapies for Helicobacter pylori infection in the United States. Aliment Pharmacol Ther 2000;14: 211-5.

164. Isakov V, Domareva I, Koudryavtseva L, et al. Furazolidone-based triple 'rescue therapy' vs. quadruple 'rescue therapy' for the eradication of Helicobacter pylori resistant to metronidazole. Aliment Pharmacol Ther 2002;16:1277-82.

165. Coelho LG, Moretzsohn LD, Vieira WL, et al. New oncedaily, highly effective rescue triple therapy after multiple Helicobacter pylori treatment failures: A pilot study. Aliment Pharmacol Ther 2005;21:783-7.

166. Wong WM, Wong BCY, Lu H, et al. One-week omeprazole, furazolidone and amoxycillin rescue therapy after failure of Helicobacter pylori eradication with standard triple therapies. Aliment Pharmacol Ther 2002;16:793-8.

167. Ali BH. Pharmacological, therapeutic and toxicological properties of furazolidone: Some recent research. Vet Res Commun 1999;23:343-60.

168. Saad R, Schoenfeld P, Chey WD. Levofloxacin triple or PPI quadruple salvage therapy for persistent Helicobacter pylori infection: Results of a meta-analysis. Am J Gastroenterol 2006;101:488-96.

169. Gisbert JP, de la Morena F. Systematic review and metaanalysis: Levofloxacin-based rescue regimens after Helicobacter pylori treatment failure. Aliment Pharmacol Ther 2006;23:35-44.

170. Gisbert JP, Castro-Fernandez M, Bermejo F. Third-line rescue therapy with levofloxacin after two $H$. pylori treatment failures. Am J Gastroenterol 2006;101:243-7.

171. Giannini EG, Bilardi C, Dulbecco P, et al. A study of 4and 7-day triple therapy with rabeprazole, high-dose levofloxacin and tinidazole rescue treatment for Helicobacter pylori eradication. Aliment Pharmacol Ther 2006;23:2817.

172. Best L, Cooper-Lesins G, Haldane D, et al. Helicobacter pylori antibiotic resistance in Canadian populations. Gastroenterology 2004;124(Suppl 2):A-189.

173. Marzio L, Coraggio D, Capodicasa S, et al. Role of the preliminary susceptibility testing for initial and after failed therapy of Helicobacter pylori infection with levofloxacin, amoxicillin, and esomeprazole. Helicobacter 2006;11:237-42.

174. Miyachi H, Miki I, Aoyama N, et al. Primary levofloxacin resistance and gyrA/B mutations among Helicobacter pylori in Japan. Helicobacter 2006;11:243-9.

175. Bogaerts P, Berhin C, Nizet H, et al. Prevalence and mechanisms of resistance to fluoroquinolones in Helicobacter pylori strains from patients living in Belgium. Helicobacter 2006;11:441-5.

\section{CONFLICT OF INTEREST}

Guarantor of the article: William D. Chey

Specific author contributions: William D. Chey, manuscript preparation; Benjamin C.Y. Wong, manuscript preparation; Practice Parameters Committee, manuscript review.

Financial support:. None.

Potential competing interests: None. 